(C) 2021, American Psychological Association. This paper is not the copy of record and may not exactly replicate the final, authoritative version of the article. Please do not copy or cite without authors' permission. The final article will be available, upon publication, via its DOI: $10.1037 /$ rev0000311

\title{
The ABC of social learning: Affect, Behavior and Cognition
}

Thibaud Gruber ${ }^{1,2}$, Marina Bazhydai ${ }^{3}$, Christine Sievers ${ }^{4}$, Fabrice Clément ${ }^{1,5}$, Daniel Dukes ${ }^{1,6}$

${ }^{1}$ Swiss Center for Affective Sciences, University of Geneva, Geneva, Switzerland

${ }^{2}$ Faculty of Psychology and Educational Sciences, University of Geneva, Geneva, Switzerland

${ }^{3}$ Department of Psychology, Lancaster University, UK

${ }^{4}$ Philosophy Department, York University, Toronto, Canada

${ }^{5}$ Cognitive Science Center, University of Neuchâtel, Neuchâtel, Switzerland

${ }^{6}$ Department of Special Education, University of Fribourg, Fribourg, Switzerland

\begin{abstract}
Author Notes
We have no known conflict of interest to disclose. Previous ideas appearing in this article were discussed at the workshop entitled "The Foundations of Affective Social Learning", Montezillon, Switzerland 2017, involving four authors (FC, DD, TG, CS), and a symposium entitled, "Social learning in development: Behavioural, cognitive and affective processes" at the European Conference of Developmental Psychology, Athens, Greece, 2019 involving three authors (MB, DD, TG). A preprint of this article has been online since Dec 2020 (https://psyarxiv.com/wyhp7/).
\end{abstract}

Correspondence concerning this article should be addressed to Thibaud Gruber and Daniel Dukes, Swiss Center for Affective Sciences, Campus Biotech, University of Geneva, Chemin des mines 9, 1202, Geneva Email: thibaud.gruber@unige.ch; daniel.dukes@unifr.ch 
THE ABC OF SOCIAL LEARNING

29 Abstract

30 Debates concerning social learning in the behavioral and the developmental cognitive sciences have

31 largely ignored the literature on social influence in the affective sciences despite having arguably the

32 same object of study. We argue that this is a mistake and that no complete model of social learning can

33 exclude an affective aspect. In addition, we argue that affect can allow bridging of the debates of the

34 unique characteristics of social learning in humans compared to other animals. We first review the two

35 major bodies of literature in non-human animals and human development, highlighting the fact that the

36 former has adopted a behavioral approach while the latter has adopted a cognitive approach, leading to

37 irreconcilable differences. We then introduce a novel framework, affective social learning (ASL), that

38 studies the way we learn about value(s). We show that all three approaches are complementary and

39 focus, respectively, on behavior towards, cognitions concerning, and feelings about objects, events and

40 people in our environment. All three thus contribute to an affective, behavioral and cognitive story of

41 knowledge transmission: the ABC of social learning. In particular, ASL can provide the backbone of

42 an integrative approach to social learning. We argue that this novel perspective on social learning can

43 allow both evolutionary continuity and ontogenetic development by lowering the cognitive thresholds

44 that appear often too complex for other species and non-verbal infants. Yet, it can also explain some of

45 the major achievements only found in human cultures.

46

47 Keywords: affect; affective social learning; behavioral processes; cognition; culture; social learning 
51 Social learning is at the heart of knowledge transmission and culture formation in many animal species,

52 including humans. However, while most of the relevant research in non-human animals (henceforth, 53 'animals') has remained at the behavioral level, presumably for fear of anthropomorphism (J. Panksepp, 54 2011b), the relevant research in humans has been mostly understood from a cognitive point of view, 55 even from a very early age. To illustrate this, one can look at the acquisition of tool use in children and 56 other animals: both learn that a tool is a particular object, but only a child is likely to learn that the tool 57 has been made by someone to achieve a particular goal (German and Defeyter, 2003). Given the underlying cognitive implications of this second step, particularly in terms of cognitive representations 59 (Gruber, Zuberbühler, Clément, \& van Schaik, 2015), it is difficult to apply the same theoretical 60 framework to animals. Furthermore, the transfer of this knowledge is thought to rely on specifically 61 cognitive social learning mechanisms and processes, including imitation and teaching, where a connection between model and learner is needed (Haun \& Over, 2013). But the establishment of such connections between two human beings most likely relies on affect, in the form of an emotional bond.

64 Yet, affects have remained almost absent from the social learning literature and debates, and are still to 65 be fully accepted by comparative psychologists as worthy of scientific study at all (de Waal, 2011).

66 Thus, crudely put, while there seems to be two stories of social learning, one behavioral and animal, the 67 other more cognitive and human, there may be good reason to believe the addition of a human, affective component would drive these two stories further apart.

However, in this article, we will not only argue for a rapprochement of these two parallel lines of research, we will also argue that social learning processes largely rely on affect, and that the latter is central to the learning process across species. In fact, affect may even provide an evolutionary bridging chapter, a chapter which points the way to a fully integrated affective, behavioral and cognitive story of social learning that includes both humans and animals. We will argue that social learning constantly requires feedback from other individuals (e.g. a parent's admonishing scowl or a partner's encouraging hug), and that emotion is the most common and effective form of this type of feedback (Clément \& 
77 Dukes, 2020). In other words, other individuals' expressions can elicit particular and specific cognitions and behaviors, leading perhaps to learning something about the object, the context, or even the expresser herself (Hareli \& Hess, 2010). It is generally understood by affective scientists that emotion motivates behavior and cognition, and to such an extent that it is difficult to imagine a model of human behavior or cognition that would not benefit from including affective processes.

One recent advance in this direction specifically concerns the interplay between behavior, cognition and emotion in acquiring cultural knowledge. Ultimately and more broadly, when a relatively tightly interconnected group of people provide the same information - that talking with your mouth full is bad, that you should support the reds but not the blues, or that the Catskills are worthy of a visit, for example - that group's values are transmitted, and the receiver of that information has socially learned that particular culture's values (Clément \& Dukes, 2013). This affective social learning (ASL) organizes various mechanisms of cognition and behavior, including emotional contagion, affective observation, social referencing and natural pedagogy along an axis of intentionality (Clément \& Dukes, 2017), and appears particularly suited for broad use across developmental, social and comparative psychology (Dukes \& Clément, 2019).

We believe that it is high time to connect the field of emotion to the behavioral and cognitive fields of social learning, and that the ASL framework can offer both continuity with other species and reasons to explain our own uniqueness. For example, it allows us to study how similar a chimpanzee juvenile observing a dominant individual's reaction before crossing a dangerous tarmac road is to a child trying to figure out from her siblings whether crossing a busy Manhattan intersection is safe; as well as how such behavior can become a socially shared feature of the given community displaying it. Hence, adopting a broad approach towards what social influences are, and the manners in which they influence others across species by learning through emotions, may offer a way to repair the evolutionary discontinuity between human cognitive social learning and animal behavioral learning. We will point out that in the search of the origins of social learning, traditionally, social influences can be split along three lines: behavioral social learning, cognitive social learning (Part 1); and emotional social 
appraisal (Part 2). We will argue that these distinctions may not be so clear, as all three could highlight a different focus on the effects that others have on us, respectively, on our behavior towards, cognitions concerning, and feelings about objects, events and people in our environment. Throughout the article, it will become explicit that these notions often collide and overlap. Indeed, generally-speaking, affective scientists would agree that a clear distinction between the cognitive, the behavioral and the affective is complicated: most definitions of "emotion" would in fact include both cognitive and behavioral aspects (Sander, 2013). This is also reflected in recent animal studies, when, compared to early behaviorist approaches, behavioral outputs are often taken as evidence of cognitive processes (see below). We will therefore strive to describe the different traditions of social learning by highlighting their focus of interest, while acknowledging that the other dimensions are often present and interrelated. Yet, by arguing that the affective dimension has remained neglected, we will describe how social learning could be defined more broadly than is usually the case, encompassing Affect, Behavior and Cognition - an $\mathrm{ABC}$ story of social learning. Adopting such an approach allows us to explore new paths, which may have led our species to its unique characteristics. Thus, in the final part of this paper, we will show that the affective dimension can be integrated in models of the evolution of culture and language, providing further clues to explaining the uniqueness of humans. Yet, first and foremost, a re-appraisal of the literature is warranted to join these three lines of research that have seemingly ignored each other, to the detriment of all three. With a view to highlighting touching points between them, this re-appraisal will be presented in terms of the increasing intentionality displayed by the learners and knowers to receive and transmit knowledge, beginning with something close to a contagion, involving minimal intentions to teach or learn, and culminating with consideration of an active, highly intentional transmission of cultural knowledge.

\section{Part 1: Traditions of social learning}

The two major traditions of social learning have aimed to understand how animals acquire knowledge in their respective environments (Zentall \& Galef, 1988), and how children acquire their knowledge and language (Tomasello, 1999). The point of this section is not to review the sometimes bitter debates 
THE ABC OF SOCIAL LEARNING

133

134

135

136

137

138

that have fueled the growing literature, particularly with respect to the specific mechanisms at work (Tennie, Call, \& Tomasello, 2009; Whiten, McGuigan, Marshall-Pescini, \& Hopper, 2009), neither to claim that the animal social learning literature is exclusively behavioral nor that the developmental literature is exclusively cognitive. Yet, by exploring the major conceptual advances made in both domains, we aim to show that they have, for the most part, followed different theoretical paths. Because we are mostly concerned with the acquisition of cultural knowledge, we will not specifically focus on the adult human social learning literature, although we will address the relevant papers when necessary.

\section{The behavioral animal social learning tradition}

The animal social learning tradition is rooted in research on behavior, as behavior is the only measurable unit when assessing beings that cannot communicate directly about their goals and beliefs with experimenters. This section will summarize many of the main ideas expressed concerning animal social learning, from Pavlovian associative learning to more cognitively grounded approaches. It will conclude by showing that animal social learning research remains rooted in behavioral explanations, mostly defined in terms of what it is missing when compared to human social learning, and characterized as lacking some high-fidelity copying mechanisms, claimed to be human-specific, such as imitation and teaching.

\section{From Pavlov to the social world}

It may be somewhat unusual to start a discussion on animal social learning by referring to Pavlovian conditioning. Yet, by frontally opposing the notion of instinct nearly seventy years ago, reference to Pavlovian conditioning started a tradition of animal learning (Krause \& Domjan, 2017) which continues to shape discussions of animal traditions and cultures today. Lehrman (1953)'s attack on the use of the word instinct triggered a revolution in our understanding of animal behavior, leading to the abandonment of a split between instinctive versus learned behavior (Bateson \& Mameli, 2007; Marler, 2004). This provided the impetus for a theory of associative learning to emerge, built on a Pavlovian 
THE ABC OF SOCIAL LEARNING

160

161

162

163

conditioning paradigm: while displaying genetic adaptations characterizing their species, animals must display enough flexibility to react to their environment in real time, thereby demonstrating a faculty for learning. The Pavlovian approach rests on Unconditioned Stimuli, which do not require prior training or learning, either posing direct threats to survival (e.g. predatory attack), or sustaining survival (e.g. food, water), so long as Unconditioned Responses are elicited (e.g. fighting or fleeing). Pavlovian conditioning allows the pairing of a Conditioned Response to a Conditioned Stimulus or context paired with an Unconditioned Stimulus. An example of Pavlovian conditioning could be Diana monkeys in the Taï Forest learning the alarm calls of birds for "leopard" and therefore enhancing their own survival by reacting adaptively upon hearing such calls (Zuberbuhler, 2000). While a review of the specifics of Pavlovian conditioning is outside the scope of the present article, it is interesting for our purpose to note that much of the literature on animal learning has been articulated about rewards, particularly foodbased, possibly because it is the easiest to implement in laboratory settings (Schultz, 2006); these rewards elicit a positive affective learning experience. In addition, other relevant notions found in the affective literature (see also Box 1) tied to conditioning are those of approach and withdrawal behavior, as well as motivational valence, which condition whether an animal will increase or decrease a behavior in light of a pleasing or aversive outcome (Schultz, 2006). For example, in the words of Schultz (2006), "punishers induce negative emotional states of anger, fear, and panic" (p.94), which influence learning. The latter also occurs in social contexts (J. B. Panksepp \& Panksepp, 2017), and beyond the context of the laboratory, as described in the next section.

\section{Social learning mechanisms in animals}

Despite the power of individual learning, one of the advantages of social life is to witness others experiencing something without having to bear the consequences (Richerson \& Boyd, 2005). For example, in the case of a first encounter with a leopard, one may not be offered a second chance to interpret the warning call correctly. The impact of associative learning has shaped both discussions of animal and human individual learning and social learning (Bandura, 1977; Shettleworth, 1998). There is still fierce debate concerning which social learning mechanisms are available to animals, with most organigrams establishing a hierarchy of social learning processes that include human-specific 
mechanisms not available to other animals. Such theoretical positioning has implications for whether we can grant the ability to possess and maintain culture(s) to other animals, if culture is dependent on particular social learning mechanisms, such as imitation or teaching (see discussion in Gruber, 2016). In this respect, stimulus and local enhancement only position themselves one step ahead of associative learning, although they display a crucial characteristic: they happen in a social context. An animal is triggered to approach a location or a stimulus because another animal was or is still currently engaging with a particular food for example. Yet, both animals individually develop a behavior in response to the stimulus, with little to no attention paid to what the other one is doing. Such triggers may be sufficient for animals to express behavior that otherwise may qualify as cultural if the correct ecological and social environments are present, but would nevertheless fall short of what is usually required to instantiate human cultural behavior (Tennie, et al., 2009). Following such reasoning, if population-specific behavioral differences documented between chimpanzee communities (Whiten et al., 1999) can be explained by low-level stimulus enhancement or local enhancement, these cultural differences have little to do with the more cognitively acquired human cultures (Tennie, et al., 2009).

Other theorists disagree with this view (e.g. Whiten et al., 2009) and argue that observational learning is necessary for some behavior to emerge. The two main processes described in the literature consist of emulation and imitation. The definition of emulation has varied in the literature (see review in Galef \& Whiten, 2017), from affordance learning to the more recently acknowledged use of the term, goal imitation. In such cases, an individual will only imitate the end result, but will not copy the behavioral form of the action (Bandini \& Tennie, 2017). Indeed, emulation emphasizes the instrumental action outcome without much regard to the process of how the goal was achieved (Whiten, et al., 2009). There are other debates about what constitutes imitation in the literature, from the distinctions between program-level and production-level imitation (Byrne, 2002), to the necessity of pairing Theory of Mind (ToM) with behavioral imitation to obtain 'true' imitation (Tomasello, Carpenter, Call, Behne, \& Moll, 2005), exemplifying the fact that the borders between behavioral and cognitive learning become ever more blurred. We believe that strong cognitive demands can be made when defining some terms, but that equal ground should be granted in their use, irrelevant of the species considered, to avoid confusion. 
216 For example, many human developmental studies use the word 'imitation' when referring to tasks that

217 may not be considered 'imitation' in the animal literature (e.g. Li, Liao, Cheng, \& He, 2019). Thus, the

218 impression that there is widespread presence of some mechanisms in humans but only limited presence

219 in other animals might, at least in part, be explained by semantic differences, rather than differences in

220 the way things actually are.

222 One uncontroversial claim is that there is limited teaching in animals. Evidence of animal teaching can be found if a functional biological definition is used (Caro \& Hauser, 1992), illustrated by famous examples, such as meerkat scorpion hunting behavior (with adult individuals disabling preys for their youngs, Thornton \& McAuliffe, 2006). Another interesting example is found in the domestic chicken, where research provides potential evidence for a large range of social learning mechanisms, including some form of teaching (Daisley, Rosa Salva, Regolin, \& Vallortigara, 2011). For example, Nicol and Pope (1996) showed that hens would increase the rate of ground scratching - when no food was available - and of palatable food pecking, without ingesting it, therefore increasing "maternal food display" (p.772), if they observed chicks feeding on seemingly unpalatable food (unknown to the hen, the food was in fact palatable). Nevertheless, there is little evidence in the literature of human-like intentional teaching (see below) in other animals. However, recent data from wild chimpanzees may challenge the scientific doxa on the absence of this type of teaching. At Goualougou, Republic of Congo, chimpanzee mothers exhibit more directional scaffolding, including direct transmission of a tool in the context of termite fishing, than chimpanzees in Gombe, Tanzania (Musgrave et al., 2020). Crucially, the former community displays a more complex tool set to transmit than the latter. These findings can not only be added to the growing evidence that social learning mechanisms are at the heart of the transmission of culture in animals (Allen, Weinrich, Hoppitt, \& Rendell, 2013; Hobaiter, Poisot, Zuberbühler, Hoppitt, \& Gruber, 2014), but also demonstrate that further work is needed to uncover potential forms of teaching in our closest relatives and other animals.

\section{The cognitive developmental social learning tradition}


THE ABC OF SOCIAL LEARNING

243

244

\section{Social learning strategies in human children}

This human social learning tradition is rooted in research on cognitive mechanisms underlying children's learning from social partners, in particular cognitions regarding children's epistemic evaluations of objects, events or social partners in their social environments. These evaluations allow children to identify people who can provide reliable information or explain ambiguous events to make appropriate decisions. Infancy presents a unique period for quickly and efficiently accomplishing a large amount of learning about the physical and social world. Children's cognitive development relies both on their first-hand exploration and on their interaction with others. Two metaphors have been used to explain children's impressive rate of knowledge acquisition: the child as a 'little scientist' - an autonomous explorer guided by experimentation, hypothesis testing and causal learning motivations (Gopnik, 2012; Piaget, 1952), and the child as a 'little anthropologist' (Legare \& Harris, 2016; Vygotsky, 1987) - a social agent embedded in the societal structure which allows for rapid and effective learning of accumulated knowledge from others. At the core of cultural transmission is the infant's capacity to flexibly and effectively engage in a variety of social learning strategies, such as observation, active information solicitation, and pedagogy (Caldwell, Schillinger, Evans, \& Hopper, 2012; Kendal et al., 2018).

Importantly, variations between cultures are also observed in the way children acquire their cultural knowledge, particularly with respect to imitation and the reliance on didactic pedagogy (Legare, 2017). Therefore, in line with a push towards less Western-centered psychology (Henrich, Heine, \& Norenzayan, 2010; Kline, Shamsudheen, \& Broesch, 2018), there have been calls in developmental psychology to increase the pool of tested infant and children populations (Nielsen, Haun, Kärtner, \& Legare, 2017). It is also important to recognize that many of the theories of human social learning based on a small subset of the human global population have been "created, reviewed and edited" (Kline, et al., 2018, p.2) by researchers from the same cultural crucible as their study population. While we acknowledge that our subsequent review will necessarily suffer from the same bias because of the paucity of data from non-Western, educated, industrialized, rich, developed (WEIRD) countries, we 
THE ABC OF SOCIAL LEARNING

270

271

272

273

274

275

276

277

278

279

280

281

282

283

284

285

286

287

288

289

290

291

292

293

294

295

296

297

very much welcome current efforts to expand the datasets on which theory of human development are built, and will refer to studies with non-WEIRD samples in the subsequent paragraphs when possible.

In the following, we cover two particularly developed human cognitive strategies in social learning: active social learning (through explicit information seeking and information transmission) and selective social learning (through early emerging sensitivity to others' cues of reliability, accuracy, confidence and credibility, as well as informants' own characteristics).

\section{Active social learning}

While children visually and manually explore their environment, track patterns, test hypotheses, make inferences, and revise beliefs based on accumulated evidence (Gopnik \& Wellman, 2012; Schulz, 2012; Shafto, Goodman, \& Frank, 2012), most of their information gathering in real life occurs in social contexts. Direct observation of others is guided by the infant learner's attentional mechanisms and allows them to acquire new information about their environment. This information could probably have been discovered on their own at a later date, but social learning facilitates more efficient sharing of knowledge among conspecifics (Galef \& Whiten, 2017; Paradise \& Rogoff, 2009). The primary social learning strategies are imitation and emulation. As excellent imitators, children can copy with high fidelity a sequence of actions demonstrated by another person to achieve a goal (Nielsen, 2006; Want \& Harris, 2002). While recent studies dispute the existence of neo-natal imitation (Oostenbroek et al., 2016; Slaughter, 2021), that humans are masters of imitation and the best at acquiring cultural information in this way is beyond doubt (Call, Carpenter, \& Tomasello, 2005; Meltzoff, 2007). In addition, only humans 'overimitate' (but see Huber, Popovová, Riener, Salobir, \& Cimarelli, 2018), routinely and faithfully copying actions demonstrated in experimental paradigms, even those that are causally and explicitly irrelevant to success in a given task (Horner \& Whiten, 2005; McGuigan, Makinson, \& Whiten, 2011). At first sight, this excess of time and energy spent copying others appears to be wasteful behavior, affording no particular evolutionary advantage. Yet, overimitation extends beyond goal-directed actions (for a review, see Hoehl et al., 2019): motivation to overimitate has been provided by cognitive explanations, such as causal understanding (Lyons, Young, \& Keil, 2007), and 
THE ABC OF SOCIAL LEARNING

298

299

300

301

302

303

more recently, by socio-emotional explanations such as the desire to affiliate with others (Over \& Carpenter, 2013) or normativity (Keupp, Behne, Zachow, Kasbohm, \& Rakoczy, 2015). Having multiple non-exclusive explanatory factors (Frick, Clément, \& Gruber, 2017; Schleihauf \& Hoehl, 2020) is useful in framing the social learning debate, and simultaneously underlines that much remains to be done to satisfactorily explain our unique capacities for acquiring information from others through imitation. For example, there are noted differences between cultures in terms of overimitation (Nielsen \& Tomaselli, 2010), which suggests a learnt component to imitation (Heyes, 2018).

Children can also obtain knowledge from others who are willing and able to share what they know via direct pedagogical instruction or intentional teaching. As compared to other social learning strategies, pedagogy, where knowledgeable individuals directly and intentionally ease the acquisition of information for naïve individuals through their behavior, facilitates acquisition of more complex knowledge and skills (Morgan et al., 2015; Zwirner \& Thornton, 2015). Obvious examples across cultures include motherese (Broesch \& Bryant, 2015; Fernald, 1985) and motionese (Brand, Baldwin, \& Ashburn, 2002) whereby adults will talk and move in a way that makes it clear to the child that they are being addressed and that there might be something to learn (Clément \& Dukes, 2017). A theory of Instructed Learning (Tomasello, 2016) argues that this social learning process evolved, not only to enable knowledge transfer, but also to establish common ground and social coherence. A theory of Natural Pedagogy (Csibra \& Gergely, 2009, 2011) proposes that humans are uniquely predisposed to learn from social partners who display ostensive communicative cues, which signal transmission of generic and generalizable knowledge. Infants' early sensitivity to these cues indicates their readiness to learn and treat this information differently. In particular, natural pedagogy allows children to acquire opaque knowledge, that is, knowledge where the immediate causal relations between elements are not readily clear. Other cognitive developmental theories similarly emphasize social facilitation of the learner's input through apprenticeship, direct demonstration and feedback as teaching models (Rogoff et al., 1993; Vygotsky, 1987). 
325 Despite the apparent dichotomy with active learning, social learning does not presume that children are 326 passive receivers of knowledge. The social learning approach indeed presupposes observing and 327 interacting with others to acquire information (Boyd, Richerson, \& Henrich, 2011; Csibra \& Gergely, 328 2009; Harris, 2012; Herrmann, Call, Hernandez-Lloreda, Hare, \& Tomasello, 2007). Knowledge 329 exchange through a variety of social learning strategies then enables transmission of accumulated 330 culture, from basic tool use to complex community rituals, passed on from one generation to another, 331 from experts to novices, from adults to children. Hence, the active social learning approach incorporates 332 the asocial (by means of individual experimenting) and social aspects as dual engines of knowledge 333 acquisition and transmission. Here, children actively participate in the social knowledge exchange by integrating what they learned through first-hand exploration, observation, imitation, pedagogical instruction or seeking others' testimony by querying them (Saylor \& Ganea, 2018) - to "gather just the information they want, on just the topic that interests them, at just the time they require it" (Baldwin \& Moses, 1996, p. 1934), and to propagate such knowledge to others. Even preverbal infants use information seeking gestures to solicit information from social partners, with their communicative strategies becoming more varied and complex with the mastery of language (for reviews, see Harris \& Lane, 2014; Ronfard, Zambrana, Hermansen, \& Kelemen, 2018).

Children also participate in active social learning through actively transmitting knowledge themselves. Not only are children efficient recipients of others' pedagogy, their own, early emerging teaching behaviors may be key to understanding the very nature of information transmission which enables cultural evolution (Strauss, Calero, \& Sigman, 2014). Despite the paucity of empirical research on the ontogeny of teaching, studies have shown that infants start to engage in basic preverbal information transmission (e.g. by using informative pointing, Liszkowski, Carpenter, \& Tomasello, 2008) and preschoolers spontaneously teach their younger siblings, who, in turn, spontaneously request teaching (Howe, Della Porta, Recchia, \& Ross, 2016). Two-year-old children selectively transmit information about novel objects functions to ignorant adults upon request (Bazhydai, Silverstein, Parise, \& 351 Westermann, 2020; Vredenburgh, Kushnir, \& Casasola, 2015). Preschoolers and older children exhibit 352 an expanded teaching strategies toolkit, gradually becoming more contingent and selective in their 
THE ABC OF SOCIAL LEARNING

353

354

355

356

357

teaching, which is dependent on the development of mentalizing, metacognition, and executive function skills (Corriveau, Ronfard, \& Cui, 2018; Gweon \& Schulz, 2019). While the natural pedagogy theory described above does not directly address children's own teaching abilities, it has been proposed that pedagogy as a teaching strategy should be applicable, both to adults and children themselves, and, as such, enables fast and efficient bi-directional transfer of culturally relevant knowledge (Strauss, et al., 2014). In support, research has documented children's own spontaneous use of ostensive cues when teaching others, including direct eye gaze, informing gestures, and contingent and verbally explicit signals (Calero, Zylberberg, Ais, Semelman, \& Sigman, 2015; Flynn \& Whiten, 2010).

\section{Selective social learning}

Posing requests for information to social partners allows children to direct their own acquisition of knowledge. As children engage in seeking information and in transmitting acquired evidence socially, their choice of social partner is often selective. This selectivity primarily manifests through sensitivity to others' cues of reliability, accuracy, confidence and credibility, as well as informants' age, ingroup status, endorsement by others, and deference to majority (Harris, 2012; Sobel \& Kushnir, 2013); such selectivity may not be limited to humans, as other species, particularly great apes, enjoy extended childhoods in which they learn their own cultural repertoire from closely related models (Lamon, Neumann, Gruber, \& Zuberbühler, 2017; Schuppli et al., 2016). Children are sensitive to others' ability to provide useful information and take an interrogative stance towards them as sources of knowledge (Harris, Koenig, Corriveau, \& Jaswal, 2018; Poulin-Dubois \& Brosseau-Liard, 2016). Understanding the ontogeny of selective social learning sheds light on the later developing, more complex accounts of selective trust in testimony (Clément, 2010; Harris, et al., 2018) and knowledge clustering (Danovitch \& Keil, 2004). As early as 8 months of age, infants treat reliable information provided through social cues, such as human faces, differently to other symbolic but non-social cues, such as arrows (Tummeltshammer, Wu, Sobel, \& Kirkham, 2014). Reliability and accuracy cues play an important role in infants interaction with social partners in their second year of life: they selectively choose to follow their gaze (Chow, Poulin-Dubois, \& Lewis, 2008), reference them in emotionally ambiguous situations (Stenberg, 2003), look longer at them upon detecting their inaccurate testimony (Koenig \& Echols, 
THE ABC OF SOCIAL LEARNING

381

382

383

384

385

386

387

388

389

390

391

392

393

394

395

396

397

398

399

400

401

402

403

404

405

406

407

2003), imitate their actions (Poulin-Dubois, Brooker, \& Polonia, 2011; Zmyj, Buttelmann, Carpenter, \& Daum, 2010), and request labels for novel objects from them (Begus \& Southgate, 2012). For instance, 12-month-olds have been shown to successfully distinguish the respective knowledgeability cues of available social partners, determine who is a better source of necessary information, and selectively refer to them when information is lacking, using pre-verbal communicative cues (Bazhydai, Westermann, \& Parise, 2020).

In addition to the epistemic indices, infants exhibit selectivity to social cues, preferentially learning from adults versus peers (Kachel, Moore, \& Tomasello, 2018; Zmyj, Daum, Prinz, Nielsen, \& Aschersleben, 2012) and from ingroup rather than outgroup members (Buttelmann, Zmyj, Daum, \& Carpenter, 2013; Gruber, Deschenaux, Frick, \& Clément, 2019). Demonstrating the increasing importance of social non-verbal credibility cues, 24-month-olds referentially learned from people who presented themselves as confident, rather than actually knowledgeable (Brosseau-Liard \& PoulinDubois, 2014). A recent set of meta-analyses reported that preschoolers exhibit selective trust based on both epistemic and social characteristics of the informants, with older children attributing more weight to the knowledge dimension rather than the social status (Tong, Wang, \& Danovitch, 2020). Furthermore, with advances in cognitive development, preschoolers flexibly update their epistemic representations of informants in light of new evidence concerning their credibility, retrospectively revising acquired knowledge if necessary (Leech, Haber, Arunachalam, Kurkul, \& Corriveau, 2019; Luchkina, Corriveau, \& Sobel, 2020).

\section{Section summary}

In this section, overall, we have shown that both the developmental and animal social literature, while sometimes intersecting, have followed different theoretical paths, particularly because of the difficulty in accessing animals' minds. Conversely, research in human children (although dealing with equally inaccessible minds in infancy) appears to often grant highly developed cognitive abilities to its subjects, 
THE ABC OF SOCIAL LEARNING

408

409

410

411

412

413

414

415

416

417

418

419

420

421

422

423

424

425

426

427

428

429

430

431

432

433

434

particularly with respect to taking others' perspectives, in line with claims of unique capabilities in their species such as ToM, imitation or teaching. Such conflicting theoretical positions have created a gap that threatens claims of continuity between humans and other animals. In addition, claims of universality remain to be tested with more non-WEIRD populations. Yet, a common point between the two traditions is that they have mostly ignored the field of the affective sciences. We believe this is a mistake, and that emotions may in fact constitute a missing bridge between the two traditions. Indeed, there is a large body of literature regarding social influence in affective sciences that may have escaped the attention of scientists in other fields, since it has not traditionally been framed in terms of social learning (Clément \& Dukes, 2017; Dukes \& Clément, 2017). Part 2 explores this aspect.

\section{Part 2: Emotions in social learning}

In a brief survey of possible systems of core social knowledge that is, innate systems that guide and navigate us in the social world throughout life, Spelke and colleagues (2013) identified three candidates: Natural Pedagogy (Csibra \& Gergely, 2011), Natural Similarity (Meltzoff, 2007) and Natural Cooperation (Tomasello, 2009). We believe that all these systems are strongly influenced by affect. Indeed, more generally, a strong case can be made that research in developmental social cognition has historically failed to sufficiently acknowledge how important infants' understanding of others' expressions is to interpersonal relationships (Reschke, Walle, \& Dukes, 2017; see also Box 1). In fact, affect appears to underpin the social transmission of knowledge, whether in terms of these systems, or through a variety of situations such as the emotional bond between learner and knower highlighted in the introduction, or the selective trust involved in the social transmission of knowledge mentioned in the previous section. The interest, enthusiasm and the passion with which one learns, or the importance of a positive relationship between students and teachers could also be added to this list (Lee, 2012; Pekrun, 2017). Such relationships have in fact often been considered under a motivational approach in the educational literature (Ryan \& Deci, 2020), reflecting “people's inherent motivational propensities for learning and growing" (p.1). While motivation is here used in a different sense than in classic 
THE ABC OF SOCIAL LEARNING

435 affective theory ${ }^{1}$, it follows that all these approaches suggest a priori strong evidence that affect is at

436 the heart of social learning.

438 One way to consider the impact of other people's emotions on our own cognitions and behaviors is in the form of social appraisal, where the social world has a direct impact on our evaluation of the objects

440 in the environment (Manstead \& Fischer, 2001). In short, when we appraise a particular object, 441 especially one about which we are not sure how to feel - an ambiguous object - we integrate how other 442 people appear to be appraising that object. Here an object can be a piece of art in a gallery for example, or a particular tool, but also an idea, another person or, in fact, any tangible or non-tangible phenomenon. As a major component of social appraisal (Clément \& Dukes, 2017), social referencing, where learners directly seek affective evaluative information from more knowledgeable onlookers (e.g. whether the object is a threat or not) and behave accordingly (e.g. Klinnert, Campos, Sorce, Emde, \& Svejda, 1983), is also of interest because it can bridge 'cognitively-demanding' to 'cognitively-simpler' mechanisms (Gruber \& Sievers, 2019). A number of classic studies (Moses, Baldwin, Rosicky, \& Tidball, 2001; Sorce, Emde, Campos, \& Klinnert, 1985; Zarbatany \& Lamb, 1985), best exemplify what is typically referred to as social referencing. In particular, Sorce, et al. (1985) watched as 12month-olds approached what must have appeared to the infants as a cliff, but what in reality was a transparent covering, that led to an alluring toy. As the child decided to move towards the toy, she was significantly more likely to cross this 'visual cliff' when her mother expressed joy or interest than fear, for example. Infants were keen on checking in with their mothers, to socially reference them as it were, but only when the cliff was a certain depth. If the 'cliff' was either too deep or shallow, the children were likely to cross or stop, irrespective of the mother's facial expression (Adolph, Kaplan, \& Kretch,

457 in press).

In a recent theoretical study, Reschke and colleagues argued that to understand others' emotions means understanding the relationship the others have to the objects in their environment, and their

461 intentionality towards those goals (Reschke, Walle, \& Dukes, 2020). Importantly, the authors 462 encouraged going beyond traditional methods of imagining how affect is communicated (e.g. facial 
THE ABC OF SOCIAL LEARNING

463

expressions) to include, for example, a repeatedly failed but ultimately completed action (à la Meltzoff) as a sign first of frustration and then relief, or even pride. A reinterpretation of three classic developmental studies involving ToM (Buttelmann, Carpenter, \& Tomasello, 2009), altruistic helping (Warneken \& Tomasello, 2006) and behavioral re-enactment (Meltzoff, 1995) - including two of the systems surveyed by Spelke and colleagues - suggested examples of how important affect might be, even if each of those studies had either implicitly or explicitly discounted emotion as a factor. Importantly, Reschke and colleagues followed up by employing a modified version of the classic behavioral re-enactment procedure study, originally carried out by Meltzoff (1995). The results bridged research on infant social referencing and psychological reasoning, by indicating that 18-moth-old infants can reference an adult's emotional expression to disambiguate a motivational state, and not just the tangible referents that are typically examined in social referencing paradigms (Reschke, et al., 2020). Meanwhile, in another paper (Clément \& Dukes, 2017), some of us have already pointed out that although natural pedagogy is almost always described in non-affective terms, emotion and emotion expressions seem to have a very important role, particularly in ostensive signaling (Csibra, 2010). Both natural pedagogy and social referencing constitute building blocks of the ASL framework, which we present in the following section along an axis of intentionality, from both learners' and knowers' sides.

\section{The transmission of value through the ASL framework}

Social information gathering is at the core of the cultural transmission of knowledge (Baldwin \& Moses, 1996; Richerson \& Boyd, 2005; Tomasello, 1999). When one thinks of social learning, it is difficult not to think of a "classical" setting where an attentive adult is leaning toward a child, doing their best to assure a specific piece of cultural information is transmitted to the new generation. This idealized image is however misleading. First, such scaffolded transmission seems to be rare, or maybe even nonexistent, in non-human primates. Nevertheless, cultural transmission is a phenomenon which is not unique to our species (Hobaiter, et al., 2014; Whiten, et al., 1999). Therefore, this form of careful pedagogy cannot be the only form of cultural transmission. Moreover, anthropologists have highlighted 
the fact that such explicit and organized intersubjective transmission is in fact quite rare in traditional societies, where children take the responsibility for learning, notably by observing the adults (Paradise \& Rogoff, 2009; Rogoff, 2003). As highlighted above, once the primacy of this image embedded in the

493 Western imagination is abandoned, the perception of social learning can become radically different.

494 Cultural transmission is no more systematically dependent on an intersubjective relationship involving

495 structured and intentional verbal exchanges: it is possible to learn simply by occupying the position of 496 an external witness, observing the behaviors of more experienced members of one's society (see also 497 Kline, 2014). Moreover, an ostensive system of communication, where each member of the interaction must make the others understand that they are willing to engage with them communicatively, is not necessary for this process to occur (Gruber \& Sievers, 2019). The onlooker can, for instance, notice that certain actions they observe trigger different sorts of results: some are welcomed with joy or interest, others with sadness or anger. These emotional reactions become, therefore, essential to evaluate the different behaviors that are perceptible to her. These affects indicate that an action is appropriate to get a certain result, whether technical (making the right move with a tool) or social (greeting a person in an appropriate way). In other words, social learning does not require for the subjects (a) to be necessarily involved in an intersubjective relationship - it can result from third-party observation, (b) to master an explicit language - it can be embedded in the interpretation of emotions.

To detail the different possibilities offered by this fresh perspective on social learning, some of us recently proposed to call this affective social learning or ASL (Clément \& Dukes, 2017). The original idea was to organize the different forms of social learning along a hierarchical line, both in term of cognitive complexity and interactional intensity (Figure 1). The most basic form of ASL is "accidental":

512 emotional contagion. The individuals that play the role of cultural models are not aware that their 513 behavior may have an impact on a learner, nor is the learner aware that they are learning anything: the model simply reacts to an event in an emotional way, as the learner 'catches' the felt emotion, and will henceforth associate the ongoing script or situation to a given affect. Imagine, for instance, a very 516 conservative family where every mention of their homeland, and each manifestation of their country's 517 grandeur, triggers a respectful silence and a sense of pride. In such a cultural environment, it is likely 
THE ABC OF SOCIAL LEARNING

518

519

520

521

522

523

\section{$524 \quad$ Figure 1}

525

526

527

528

529

530

531

532

533

534

535

536

537

that the usual triggers of such affects (the first notes of the national anthem, the raising of the flag, etc.) will trigger a similar emotion. In such circumstances, the new members of a group will 'learn' to value certain objects, events or persons in a way that is considered as culturally appropriate. This basic form of social transmission does not involve either intentional communication by the model, nor an interrogative attitude by the learner, who is taken by the emotionally charged context.

The ASL scale according to three dimensions of intentionality, trust and social interaction

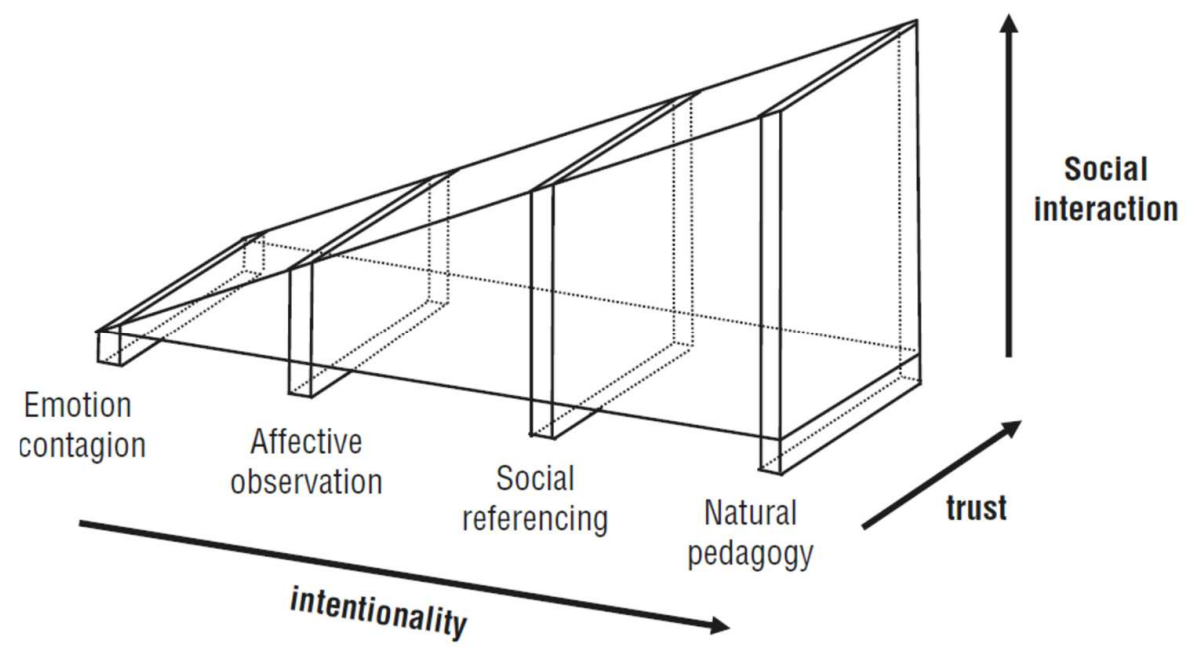

Note. Adapted from Dukes, D., \& Clément, F. (Eds.). (2019). Foundations of Affective Social Learning: Conceptualizing the Social Transmission of Value. Cambridge: Cambridge University Press. Page 11. Reprinted with permission from Cambridge University Press.

The second form of ASL requires the learner to intend to make sense of something that she is observing, hence the name, affective observation. Typical cases are situations where the curious agent is trying to actively figure out how to behave given that the meaning of the context is still obscure for her. She will therefore explore her environment in search of a model whose reaction will inform her about the appropriate way to react in this context. Imagine that someone is invited to a party in a country where she has just arrived and where everything looks very exotic to her. Once arrived, she will rapidly scan the other guests to see how they are behaving, and observe the reactions displayed by the hosts before 
557

she decides on a way to greet them: how broad should the smile be, how low should the respectful bow go? In this case too, the models do not have to intentionally communicate some culturally relevant information; the information is out there, at the disposal of any observer. Alternatively, such observation of the affective signals of a model may lead to the communication and integration of implicit biases, even if the model is unaware of those biases (Halberstadt, Hagan, \& Lozada, in press). Note that in none of these cases, did the learner have to master the local language to either figure out what she was supposed to do, or what she was (not) supposed to learn.

The next step in ASL requires explicit emotional communication. This time, the subject is ostensibly referring to the model for help, not knowing how to behave when confronted by an ambiguously valenced object (e.g. one that may or not be dangerous), hence the name: social referencing. This phenomenon has been discussed above: a visual cliff experiment stages a clear situation of intersubjectivity, where the two participants are intentionally engaged in a communicative exchange. Infants are requesting information and adults are intentionally providing effective cues to shape their child's behavior. The child behaves (and perhaps, thinks) in reaction to their parent's affective signal: a positive expression signaling "Safe. You can cross", while a negative expression signals "Danger. Do not cross". However, this interaction does not necessitate full-blown informative meaningful signals used in communicative interaction (e.g. expressed through verbal language): both the request (interrogative gaze) and the response (emotional expression) can be wordless.

While affective observation and social referencing originally stem from a division of the concept of social appraisal introduced by Manstead and Fischer (2001), the last type of ASL, natural pedagogy (as described earlier), will be more familiar to scholars of social learning. It requires more cognitive abilities from the model because the latter undertakes to transmit complex abilities or knowledge in a structured way, checking as things progress that the learner is incorporating the information; this process is classically called pedagogy. Even if this transmission does not necessarily require linguistic exchanges (it could involve gestures, for instance), the models must possess some metarepresentational abilities. They should notably represent the present informational state of the learners and imagine a strategy to 
566 help them acquiring the new pieces of knowledge. By observing the learners' progress, they should 567 evaluate their understanding and regulate the rhythm of teaching in accordance. As in all these examples 568 of ASL, the affective bond between the social partners (labelled as 'trust' in Figure 1), promotes the 569 successful transfer of the information. Here, in (natural) pedagogy, we can imagine a longer, more 570 emotionally engaged discussion about the value of a particular toothbrush, team or tenet. We are 571 therefore dealing here with a complex intersubjective interaction, with both parties deeply immersed in 572 an intentional activity that is certainly cognitive, but also highly affective. Each stage of learning is 573 welcomed with a positive reaction by the model and, when progress is made, a feeling of satisfaction is 574 also experienced by the learner.

576 While natural pedagogy has been markedly absent in all species other than humans, all three of the 577 previous steps are likely to appear, to various degrees, in a number of species, offering a valid 578 evolutionary pathway to explore both humans and other animal social learning (Gruber \& Sievers, 579 2019). An interesting comparative aspect additionally lies in the fact that while animals are often 580 described as having very little control over the display of their emotions (but see Gruber \& Grandjean, 581 2017; Tomasello, 2008), it is in fact quite rare for a human observer to notice emotional changes in 582 animals with the exception of strongly marked emotional reactions (e.g. fear or aggression). Yet, as 583 Schuppli and van Schaik (2019) note: "in the absence of any discretely displayed emotion, the emotional 584 engagement of the role model may be on a much more subtle level. Some degree of joy or happiness 585 may result from having found a food source, even if it is an ordinary one. Building a nest might be 586 connected to the anticipation of getting to lie down and rest soon. Complex foraging tasks (e.g. tool 587 use) may come along with a certain excitement about getting to eat a particularly tasty or satiating food 588 item. These emotions (or temporary affective states) of the role model may be enough to elicit an 589 emotional engagement in the learning..." (p.34, the original authors' emphasis). Note also that some of 590 the described examples can alternatively also be described as possible motivations to act (Frijda, 2010). 591 Overall, the ASL framework allows exploration of an additional dimension of learning, and to 592 operationalize the inclusion of emotion in the social learning debate. 
THE ABC OF SOCIAL LEARNING

594 ASL and emotional feedback within the existing literature

595

596 We see both similarities and differences between the ASL framework (and the emotional feedback it 597 predicts and allows) and other models in the literature, both on a small and a large scale. The most 598 similar large scale model was proposed by de Waal: the Bonding and Identification-based Observational 599 Learning (BIOL) model (de Waal, 2001; de Waal \& Bonnie, 2009) with BIOL defined as "a form of 600 learning born out of the desire to belong and fit in" (de Waal \& Bonnie, 2009, p22). We see many 601 convergences with this model, particularly its departure from the classic view (e.g. Bandura, 1977) that 602 social learning only occurs when there are extrinsic rewards either for the model or for the observer, a 603 focus on rewards still very present in the animal learning literature today. The BIOL model predicts that 604 social learning will be guided by social relations, and several instances of supporting evidence have 605 appeared in the context of cultural and communication acquisition in animals (Fröhlich, Müller, Zeiträg, 606 Wittig, \& Pika, 2017; Lamon, et al., 2017; Mann, Stanton, Patterson, Bienenstock, \& Singh, 2012). 607 However, there are important differences between BIOL and ASL, the most important of which is that 608 BIOL focuses on the social relationship between two conspecifics and what underpins that relationship $609-$ the bonding and identification - rather than the consequences of that relationship. In contrast, while 610 ASL does indeed highlight the importance of that relationship, especially in the later steps, it focuses 611 more on how much the successful transmission of value(s) is a result of the established relationship, 612 whatever it is (e.g. one would still learn something from an unrelated man screaming while running away from a subway entrance).

615 In terms of similar smaller scale theoretical frameworks and models similar to ASL, one concerns the 616 learning of fear, and has the advantage of offering numerous cross-species comparisons. Previous work 617 carried out by Olsson and Phelps (Olsson \& Phelps, 2007) points out that it is particularly important to 618 try and learn from others' relations to objects in the environment when the objects can be risky, for example, by recognizing other people's fear (see also Part 1). In one experiment, Olsson and Phelps 620 (2004) compared the use of Pavlovian conditioning, observational learning and vocal 'instruction' in 621 the learning of a painful experience (electric shocks). All three groups learned to associate the stimuli 
THE ABC OF SOCIAL LEARNING

622 (angry faces) with the shocks in an unmasked condition (i.e. when the stimulus was clearly perceptible

623 to the participants); however, only participants in the Pavlovian and observational conditions still

624 reacted physiologically to the conditioned stimuli when they were masked. Hence, being told that a

625 particular neutral stimulus is dangerous only worked at a conscious level, while experiencing the

626 consequences oneself or observing someone else suffer the consequences, was enough for the reaction

627 to become automatic. There is substantial cross-species support for the idea that fear can be learned

628 from others, particularly when the stimulus is naturally aversive. In one such study, mice that observed

629 biting flies attacking other mice reacted just as strongly as the models to the flies 24 hours later, despite

630 being exposed to harmless flies (Kavaliers, Choleris, \& Colwell, 2001).

631

632 According to Olsson and Phelps (2007), social learning "lies at the core of the forces that create and 633 maintain culture, which might then affect biological evolution", with "social fear learning offering the 634 opportunity to study the transmission of biologically relevant information between individuals" (p. 635 1100). This echoes our description of ASL as a conduit for the social transmission of social value, and 636 a means by which culture can be transmitted and perpetuated (Clément \& Dukes, 2017). Phelps and 637 Olsson limit their claims to the learning of fear and threat within a Pavlovian reward-based model 638 (Debiec \& Olsson, 2017; Olsson, Knapska, \& Lindström, 2020; Olsson, Nearing, \& Phelps, 2007; 639 Olsson \& Phelps, 2004), citing evidence related to naturally aversive stimuli. In line with this, a recent 640 study of the social learning of fear in fear-relevant (naturally aversive) and fear-irrelevant stimuli, 641 corroborating earlier findings (Hygge \& Öhman, 1978), revealed stronger acquisition effects for fear642 relevant (snake and spider), verbally conditioned stimuli compared to fear-irrelevant (bird and 643 butterfly), verbally conditioned stimuli (Mertens, Raes, \& De Houwer, 2016). Yet, we argue that 644 affective evaluations can be learned about objects that have no naturally occurring aversive quality. A 645 particular haircut, a certain style of dance, or a specific idea can become a source of ridicule or respect, 646 depending on how those around us evaluate them. Objects that may have left an observer entirely 647 indifferent can also acquire value through exposure to the affective reaction of others, whose social 648 appraisal works best in ambiguous situations (Bruder, Fischer, \& Manstead, 2014). 
THE ABC OF SOCIAL LEARNING

649 Overall, the ASL framework fits well with other large or smaller scale models that have strived to 650 include an affective dimension to learning. However, we believe that by highlighting the role of affect 651 in the social learning process, ASL contributes to integrating affect into models of social learning.

652

Defining 'values': from 'relevant behavior' to complex 'social values'

654

ASL was originally defined as the social learning of values (Clément \& Dukes, 2017). For this concept to be relevant across sciences, one needs to define clearly what the term 'values' encompasses. On the one hand, the term 'values', at its core, can be understood through general emotion theories, encompassing for example dimensional models of emotions (Sander, 2013). In particular, common valence-based distinctions are found between "positive" and "negative" emotions, evidenced by Tomkins' (1963) influential division between positive and negative affects. Such distinctions are found in most models of emotions. Hence, for affective scientists, the notion of social value may find a place at the core of affective theory. However, values can also be discussed as the patriotic feeling towards the flag we discussed above. This is an equally valid interpretation of the term, yet it also raises several questions. While this value can be acquired through seemingly simple cognitive processes that do not require ostension or directed teaching, it is unlikely to be found in non-human animals, nor in ancient hominin societies, including our direct ancestors, that did not possess such notions as patriotism. In contrast, the positive/negative dichotomy may be present across species, itself requiring little conceptual understanding, while still allowing the evolutionary possibility of metacognitive thinking about such values. For example, Panksepp discusses a definition of affective consciousness as "brain states that have an experiential feel to them" (J. Panksepp, 2005, p.32), and argues that reflective sensory-

671 perceptual feelings and emotional-motivational experiences, completed by secondary-consciousness 672 (which refers to the capacity to have thoughts about external events), are present to some extent in other animals. Yet, he excludes a third layer of metacognitive reflection upon those brain states, which would be limited to humans. We believe that such a distinction and this three-step consciousness scale of affect is of particular interest from both a comparative and developmental perspective. 
THE ABC OF SOCIAL LEARNING

677 From a developmental perspective, the transmission of these 'lean' values appears more

678 straightforward, with numerous examples documented over the last 40 years (Sorce, et al., 1985). A

679 relevant question here is at which point such reasoning becomes self-conscious in the child's mind,

680 reaching the third metacognitive level hinted at by Panksepp. In other words, many seemingly complex

681 cognitive processes in developing infants and children may be more simply explained by 'lower level'

682 ASL steps that do not require explicit complex processes such as ostensive behavior or complex 683 metacognitive reasoning abilities. To illustrate this, one can look at the relationship that young infants 684 establish with artifacts across development. The latter is first described with 2-year-olds reaching an 685 understanding of some properties of artifacts but without forming an overall concept of tools (Mandler, 686 2007), followed by 3-year-olds understanding that tools are 'made for' a given purpose and selecting 687 them accordingly (DiYanni \& Kelemen, 2008). When close to six years of age, children start 688 understanding that a tool has been intentionally manufactured by a designer to fulfil some function 689 (Kelemen \& Carey, 2007). This also represents an important cognitive and representational shift from 690 age five, when the function of an artifact is not completely clear in the child's mind, fulfilling any goal 691 a user might have, to age seven, when the function has become that of the artifact's typical or intended use (Defeyter \& German, 2003). In other words, according to this cognitive framework, it is only by age five that ostension or metarepresentative abilities are needed to fully acquire the concept of tools. Yet, the preparatory work before that age may be accomplished through the assistance of ASL processes that allow particular objects to acquire value as tools in the child's mind. On the other hand, whether tool-using animals are ever to grant a value to a particular tool remains to be investigated, with the possibility of some objects acquiring a relevance in some animal groups, which disappears in those that do not make use of these tools, seeding cultural differences (Gruber, Muller, Reynolds, Wrangham, \& Zuberbühler, 2011).

\section{Section summary}

In this section, overall, we have shown that the affective literature includes many notions also found in

704 the classical social learning literature and can be integrated into a general discussion of social learning. 
THE ABC OF SOCIAL LEARNING

705

706

In particular, we have proposed that the ASL framework allows investigation of such dimensions, and is crucially organized according to the same intentionality scale found in the developmental and behavioral literature (Clément \& Dukes, 2017; Dukes \& Clément, 2017). We also argued that the ASL framework is particularly suited to study cultural transmission across species and developmental stages by allowing the existence of mechanisms which vary in their cognitive demand. In the following section, we aim to expand this approach to highlight the fact that no current model of social learning can in fact make complete abstraction of emotion, and that in reality, they are, possibly unconsciously, already including them in their models as notions in developmental cognitive research.

\section{Part 3: Integrating the three approaches of social learning}

In this section, we evaluate how the different approaches to social learning (behavioral, cognitive and affective) overlap in their object of study, and argue that separate domains of study should strive to adopt a common language where an affective layer is acknowledged. We illustrate our point with two examples taken from the literature. First, we argue that what developmental psychologists often study as 'curiosity' can also be investigated under the affective notion (or emotion) of 'interest', and that this notion can also be found in animals, particularly when formalized under the notion of "peering behavior'. Second, we argue that social referencing, in itself, offers ways to navigate between emotionally and cognitively-loaded approaches. Finally, we begin to introduce how neuroscience can contribute to integrating these three approaches of social learning, employing the research in empathy as an example, as it too strives to integrate cognitive and affective aspects, thus providing a blueprint for investigating the neural correlates of affective, behavioral and cognitive social learning.

\section{Emotional interest and epistemic curiosity}

As we argue for an integration of the three lines of research on social learning, the distinction between what is affective, behavioral and cognitive often blurs. One such blurring distinction is that between a (non-affective) epistemic curiosity and the emotion of interest. Confusingly perhaps, the term epistemic 
THE ABC OF SOCIAL LEARNING

733

734

emotion actually often includes phenomena that would not normally be included as emotions (ArangoMuñoz \& Michaelian, 2014; Meylan, 2014). While it is certainly possible to make a case to maintain these two phenomena as distinct (Hidi \& Renninger, 2020), we argue that there is much reason to analyze them together. Indeed, they have even been used synonymously by some researchers (Silvia \& Kashdan, 2009). Crucially, they provide an example of a cross-specific and cross-developmental application of our theoretical position.

Curiosity is broadly defined as active information seeking motivated by internal rather than external rewards, and the term captures a range of behaviors, including those that pertain to infants, from targeted search for a particular bit of information to broad sampling of the environmental affordances, and from tactile stimulation seeking to the pursuit of knowledge. Curiosity is most often analyzed from a cognitive perspective and as a cognitive phenomenon (Bazhydai, Twomey, \& Westermann, 2020; Berlyne, 1960; Gottlieb \& Oudeyer, 2018), often taking place in social contexts, manifesting in infants' active social learning through interaction with suitable (familiar, friendly, or knowledgeable) social partners, and ultimately helping fulfil infants' information seeking goals and maximizing their epistemic benefit. A different take on curiosity (as here defined, 'a desire') is to approach it as an emotion: interest. Such a reading does not change fundamentally the way one approaches curiosity. As part of an inherent interplay between autonomous and social processes, it is a catalyst of social learning and epistemic development, broadly speaking. Yet, this also underlines the blurry lines between cognitive and emotional approaches at a developmental stage, where it is difficult and perhaps inutile to try and parse what is cognitive and what is emotional.

An important comparative aspect here lies in the existence of a similar mechanisms in non-humans during learning acquisition: peering behavior, that is the attentive close-range watching of the activities of an (often older) conspecific (Schuppli, et al., 2016; Schuppli \& van Schaik, 2019). This offers ways of discussing behavioral continuity in knowledge transmission, particularly with our closest relatives, the great apes. Orangutans, in particular, acquire much of their knowledge through peering behavior; summarizing a large body of work in one location in Sumatra famous for its tool-using orangutans, 
THE ABC OF SOCIAL LEARNING

761 Suaq Balimbing, Schuppli and van Schaik (2019) show that peering behavior could be involved in the

762 acquisition of 191 different skills and knowledge elements spanning knowledge of food species to consume, moving habits, social behavior as well as tool use. Favored models for infants were adults, with often very little information taken from juveniles and other infants; yet, interestingly, during late juvenility (corresponding to the human adolescence), the most frequent peering targets turned out to be other juveniles, mirroring other findings in the development of chimpanzee vocal behavior (Laporte \& Zuberbühler, 2011). Overall, these findings show that there is much ground for comparison between human and nonhuman curiosity and interest.

769

Social referencing: how affective is it?

A second example of the blurred distinction is that of social referencing as an essentially emotional or cognitive mechanism. Several theories requiring different levels of cognitive complexity have been proposed to explain the development of social referencing behavior. To adjudicate between low-level, associative, and higher-level, cognitively rich explanations, a developmental perspective can be adopted. According to such an approach, social referencing in the first year of life may constitute information seeking with rudimentary understanding of intentional communication, which is nevertheless sufficient to solicit timely and reliable transfer of knowledge from social partners. An important point of discussion has been whether social referencing in uncertain situations constitutes information seeking or attachment motivated behavior (Stenberg \& Hagekull, 2007; Striano, Vaish, \& Benigno, 2006). Overall, studies provide support for the expertise rather than attachment (or comfort seeking) account of social referencing, proposing that infants are sensitive to the social distribution of knowledge (Feinman, Roberts, Hsieh, Sawyer, \& Swanson, 1992; Stenberg, 2013). In particular, when a situational expert is an unfamiliar experimenter, infants are more likely to refer to them rather than their primary caregiver or another less knowledgeable adult, who in this context is as uncertain about the situation as the infant herself (Stenberg, 2013). 
788 Whether or not preverbal infants have a full grasp of intentionality of their communicative acts, they do 789 learn a great amount of new and useful information through initiating a social gaze, which may be a 790 genesis of social information exchange. Some studies suggest that social referencing serves a 791 cognitively rich function of information seeking, going beyond the emotional 'go/no-go' checking in 792 as potential proto-interrogative, requestive acts, which develop before interrogative pointing (Begus \& 793 Southgate, 2018; Harris \& Lane, 2014). For example, experimental reports focus on situations of 794 cognitive-perceptual ambiguity rather than unpleasantness or perceived danger - situations of epistemic uncertainty featuring a lower threshold of uncertainty than the typical highly emotionally arousing paradigms. Reports show that infants refer to their social partners when their expectations are violated (Dunn \& Bremner, 2017; Koenig \& Echols, 2003), upon detecting humorous situations (Mireault et al., 2014), when facing uncertainty about object-label relationships (Bazhydai, Westermann, et al., 2020; Hembacher, deMayo, \& Frank, 2020), or needing information about hidden object location (Goupil, Romand-Monnier, \& Kouider, 2016). These studies challenge the long-standing view that social referencing seeks others' socio-emotional engagement and is not fully intentionally communicative until the second year of infant's life (Baldwin \& Moses, 1996; Schaffer, 1984). Instead, they suggest that social referencing is an active communicative behavior allowing preverbal infants to resolve not only affective, but also epistemic uncertainty in social learning contexts.

In sum, well established accounts of social referencing propose that children refer to social partners to gather their reactions to uncertainty, which is affective in nature, and to determine how to appropriately react to it. However, with development, the same behavior can become less emotionally laden, transforming into strategic information seeking rather than social appraisal seeking. Bridging the cognitive and affective social learning aspects, we argue that social referencing lies at the heart of children's social acquisition of knowledge, epitomizing the parallel between the affective and cognitive dimensions. Among examples of these two sides, are infants' social referencing towards their caregivers upon encountering not only an unexpected emotional but also a cognitive challenge (as described above). 
THE ABC OF SOCIAL LEARNING

816 How much of this is present in non-humans is worth investigating. Non-humans are sensitive to both

817 conspecifics' and non-conspecifics' emotional cues. For example, vervets (Chlorocebus pygerythrus)

818 are sensitive to meaningful alarm vocalizations that are mostly regarded as emotional (Price et al.,

819 2015). These cues might even be emitted to aid learning (Seyfarth \& Cheney, 1986). Elsewhere, some

820 of us have argued that social referencing is particularly promising to study the acquisition of animal

821 cultures and signals (Gruber \& Sievers, 2019) as it represents a good compromise, by being less

822 cognitively demanding than traditional learning processes, yet well suited to the emotional dimension

823 inherent to animal learning (LeDoux, 2012; J. Panksepp, 2011a). For instance, the way members of a

824 stick-less chimpanzee community proceed with intentionally removing sticks from the hands of their

825 offspring may qualify as an example of social referencing (or even pedagogy), leading ultimately to the

826 failure of these chimpanzees to represent sticks as tools (Gruber \& Sievers, 2019).

828 Neural substrates of cognitive and emotional processes overlap

829

Discussion concerning the similarities and differences between what is cognitive and what is affective can be found in several of the disciplines that contribute to the affective sciences. For example, 'affective neuroscience', a term first coined in the 1990s (J. Panksepp, 1998), has from its very inception addressed questions concerning how to characterize cognitive and affective processes and to identify areas and networks of the brain that could be said to be wholly one or the other, or indeed both. While such discussions continue, one area of research that can perhaps serve to illustrate such debate and suggest how to ground the current approach on a more neuroscientific footing is the research on empathy. The cognitive and affective aspects of empathy, and their overlap, have indeed been the focus of much interest. Often defined from a mentalistic perspective as putting oneself in someone else's shoes (Baron-Cohen, 2005), the cognitive approach, fully at work during the teaching process displayed by humans, can be contrasted with a more emotional approach to empathy, a useful notion particularly for animals and young infants (de Waal \& Preston, 2017). Emotional empathy includes mechanisms 842 such as emotional contagion, which we have already highlighted as a main component of ASL, 843 suggesting perhaps that empathy should also be taken into more consideration in future studies of ASL. 
844 For example, in a more complex form of empathy known as targeted helping (de Waal \& Preston, 845 2017), a chimpanzee finds the specific tool that another needs in an experimental context (Yamamoto, 846 Humle, \& Tanaka, 2012), a result directly relevant to the investigation of teaching behavior in the wild 847 (Musgrave, et al., 2020). Research on the neural correlates of empathy, which has flourished over the last two decades, may allow characterizing the mechanisms at work during the different components of this complex phenomenon as cognitive, affective, or both (de Waal \& Preston, 2017).

In particular, neuroscience has allowed the identification of regions that are more concerned with affective empathy than with cognitive empathy (de Waal \& Preston, 2017), but also regions that are involved in both processes such as the anterior middle cingulate cortex (aMCC), located at the extremity of the anterior cingulate cortex (ACC). Alongside structures such as the amygdala (often involved in fear learning, but generally present in most emotionally-salient processes) or the insula (found particularly in connection to disgust), the ACC is known for its involvement in affective processes, particularly as an integration hub between the affective limbic system and the more cognitive prefrontal cortex (Sander, 2013; Stevens et al., 2011). Another region of overlap between cognition and affect, and itself also an integration hub, is the Inferior Frontal Gyrus (IFG), involved in cognitive sequential structures, language and emotion evaluation (Greenfield, 1991; Gruber \& Grandjean, 2017; Koechlin \& Jubault, 2006). Interestingly, the IFG is also part of the human mirror neuron system, which has been connected to a large range of human socio-cognitive abilities, including empathy (but see Hickok, 2014; Iacoboni, 2009). While we will not engage here in the debate on the role of the mirror neuron system in these abilities, their potential involvement in chimpanzee imitative behavior during tool use acquisition (Fuhrmann, Ravignani, Marshall-Pescini, \& Whiten, 2014) provides another bridge between empathy and social learning research; with the former providing a blueprint to investigate the affective and cognitive aspects of social learning concurrently through neuroimaging, in a comparative (e.g.

\section{Section summary}


872 In this section, we have seen that major objects of research overlap across the three approaches,

873 sometimes being referred to by different names (cognitive curiosity versus emotional interest) or by the 874 same one (social referencing). We have argued that associating both a cognitive and affective dimension

875 appears the most promising approach, explaining the behavior inherent to social learning, and 876 illustrating that such a position is shared in the study of complex phenomena such as empathy. Besides

877 the obvious connections of the latter with ASL, we believe that the neuroscientific research on empathy 878 offers a way forward to integrate the affective and cognitive dimensions of social learning. We have 879 also argued that adopting a stance combining cognitive and affective dimensions allows evaluation of 880 the predominantly behavioral animal literature within the same theoretical framework and hence promote continuity between humans and other animals. In the final section, we present our 882 implementation of an $\mathrm{ABC}$ approach to social learning. To do so, we propose a radical extension of the 883 ASL framework as a tentative move to fully integrate the three traditions into one complete story.

\section{Part 4: The $\mathrm{ABC}$ of social learning}

\section{ASL as an extended backbone to models of social learning}

ASL in its four-step form may not be exhaustive in covering all possible cases of learning involving affective input by a knower. For a case of social referencing, the learner seeks out information from the knower by focusing on the knower's expressive behavior by intentionally establishing eye-contact.

892 According to the ASL framework, the knower provides information intentionally through displaying a 893 befitting affective state. While at this stage limited active exchange of meaningful, informative signals is necessary, this is a mandatory requirement for natural pedagogy. In turn, for a case to count as natural pedagogy, ostensive communication of meaningful signals (e.g. words or gestures) is necessary (Gruber \& Sievers, 2019). Given how ostensive communication is often described as cognitively challenging, requiring layers of meta-representations and a full-blown theory of mind, only (some) human 
THE ABC OF SOCIAL LEARNING

898

899

900

901

902

903

904

905

906

907

908

909

910

911

912

913

914

915

916

917

918

919

920

921

922

923 All the illustrated examples above in comparative and developmental psychology suggest that the

924 various existing steps of the ASL framework are part of a continuum. Yet, this limitation of considering

925 ASL as a four-step framework would be rather structural, and was highlighted here in this way to offer

interactions fall under these stringent requirements, and any kind of simpler communicative display by knowers would not meet the criteria. This concerns, for example, cases that involve an active exchange of signals between learner and knower, e.g. with the knower producing behavior or signals in accordance to their goals towards the learner, but without being interested in accessing the mind of the latter. These cases are not described in the ASL framework, as they go beyond what is generally labelled social referencing, but are not yet to be counted as natural pedagogy. Cases like this may involve active teaching to a certain degree. Most examples of animal teaching rely on so-called innate processes that appear far from the intentional transmission found in humans (see above). Yet, an emotion-based social learning framework may explain the recent claims of chimpanzee teaching made by Musgrave, et al. (2020) without having to argue for additional associated cognitive complexities of intention-based teaching. The directional scaffolding the authors describe could indeed form the basis of a cultural transmission of a relevant behavior for chimpanzees amongst a complex dataset.

Another possible scenario involves learners actively producing meaningful signals, either ostensively or not, and knowers simply responding behaviorally, showing affective states, but not engaging in communication (think for example of a curious child observing a lion escaping its cage at the zoo and actively seeking to exchange information about this novel setting with her parents while seeing them suddenly screaming in fear). Real cases of interactions that facilitate learning may also in general not be as clear-cut as required by experimental paradigms. For instance, when chimpanzees cross a road, the interaction between knowledgeable individuals crossing first, waiting for, and interacting more or less actively with young individuals who are scared of crossing the road (see Table 1), could entail very different levels of active influencing by the knower and active requesting of information by the learner, leading cases to be classified as social referencing or the possibility of extending beyond the borders of the former. 
a common language between well-defined concepts in both affective science and developmental science

927 incorporated into a hierarchy of processes that involve affective states as elements that facilitate

928 learning, topped by the most distinctively human and cognitively complex form of active teaching. At

929 the theoretical level, the scope of the ASL framework is indeed about describing a knower's emotional

930 states impact on the process of social learning in a learner, and in particular, ASL is about learning how

931 to feel about something, how to value it. One way to deal with this issue of precisely attributing a case

932 to a given category would be to introduce further steps into the framework. While it may be impossible

933 to distinguish steps to cover all possible cases, they will all be situated along a continuum involving

934 more or less active communication and affective input on both the knower's and learner's sides. We

935 thus argue that ASL can constitute a backbone to an affective model of social learning across species

936 (Figure 2), irrespective of whether a particular step must be identified, as long as the particular cognitive

937 requisites (e.g. ostension, representational level, degree of interaction between learner and knower, see

938 Gruber \& Sievers, 2019) can be described. Overall, our approach aims to illustrate that whether

939 individuals seek to exchange information that is itself either affective or not (e.g. seeking an object's

940 label rather than seeking positive emotional feedback), all learning is influenced by emotional cues, if

941 not completely embedded in emotional interpersonal communication.

943 As the clean lines of what is affective, behavioral and cognitive blur, it is worth considering the original

944 ASL framework again. In Part 1 of this paper, we described the animal behavioral and human cognitive

945 traditions of social learning in terms of increasing intentionality, as the cognitive mechanisms involved

946 become more complex. In Part 2 and 3, we described how there was an affective base underpinning all

947 of these mechanisms whether explicitly in ASL, or implicitly in the other traditions. In the ASL

948 framework, this affective component is held to be equally important across all of the mechanisms, and

949 the same is true here. And finally, with a view to integrating these models, it can be observed that there

950 is increasing social interaction, or behavior, on a third axis (Figure 2). As argued above, the ASL

951 framework can constitute the structure of an $\mathrm{ABC}$ approach that integrates all three strands of the social

952 learning story.

953 
956 ASL as a backbone to an integrated approach of affect, behavior and cognition to social learning.

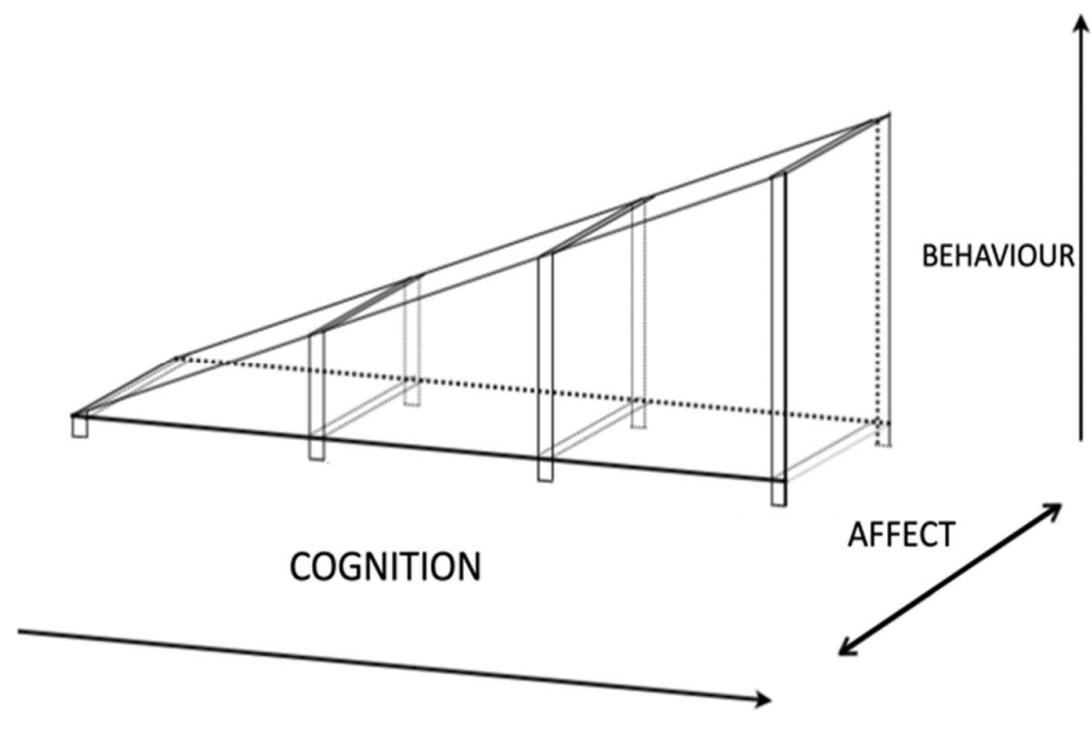

957

958 Note. As in Figure 1, the direction of the arrows for cognition and behavior indicates that they can only grow in terms of content and complexity. However, the bidirectional arrow for affect suggests that the affective dimension is more or less developed depending on the species considered as a whole. Adapted from Dukes, D., \& Clément, F. (Eds.). (2019). Foundations of Affective Social Learning: Conceptualizing the Social Transmission of Value. Cambridge: Cambridge University Press. Page 11. Reprinted with permission from Cambridge University Press.

\section{Using affect as an evolutionary and developmental bridge}

One may raise the paradox of including emotional contagion in an account of learning about objects. Social learning is characterized by there being three relational corners - the learner, the knower and the object - even if, unlike in social appraisal, there is no explicit object in emotional contagion strictly

970 speaking (Parkinson, 2011). While we motivated emotional contagion's inclusion earlier from a 971 theoretical point of view, emotional contagion proper may nevertheless not find its place in an account 972 of social learning other than as an endpoint, a boundary condition with any slight increase of 
973 intentionality leading to social learning, or a zone delimiting what is non-object centered emotional

974 contagion and what is object centered affective observation. Yet, emotion contagion has often been 975 used as a baseline explanatory process in animals (e.g. Wheeler \& Fischer, 2012), underlying the interest 976 in keeping this notion in the ASL framework, bringing continuity between humans and other animals 977 from a comparative and evolutionary perspective. In effect, the use of this 'low-cognition process' as 978 an explanatory factor contrasts very much with the evolutionary explanations traditionally offered to 979 explain the occurrence of features such as language conventions and learning of opaque knowledge, 980 which are said to rely on complex cognitive capacities such as meta-representation, mindreading, or 981 perspective taking (Townsend et al., 2017). All of those are high-cognition complex features (but see 982 Southgate, 2020), which in part makes the presence of some of them in infants and young children 983 almost impossible to explain, or their cognitively-loaded explanations highly questionable. For instance, 984 for young children to acquire opaque knowledge, as reviewed above, it is often required that children 985 display the ability of perspective-taking, i.e. that they take the perspective of the knower to grasp the 986 latter's intention, allowing them to imitate a given action (Tomasello, et al., 2005). It is additionally 987 suggested that to do so, children must display a fully developed ToM, even though the latter may only arise around four years of age, suggesting the need for alternative explanations in younger children. The same holds true of other animals. Elsewhere, some of us have argued that some animals are likely to exhibit the cognitive abilities for at least three of the ASL steps (Gruber \& Sievers, 2019), including social referencing, suggesting that any step in between can be identified as well. However, it remains unlikely that any non-human may engage in human-like natural pedagogy.

994 Yet, by acknowledging that affective states may play a big role in acquiring knowledge, we argue that 995 assumptions regarding cognitively loaded features (e.g. metarepresentation) can be downgraded, being 996 in fine applicable for both non-humans and very young children. For example, learning from complex 997 behavior only requires learners to attend to certain aspects of the behavior displayed by the knower to infer the knower's intention linked to the behavior. Capacities such as perspective taking (but also 999 shared attention) can, however, be established through the affective states in the knower perceived by 1000 the learner. By displaying a certain affective state towards an object, for instance, or a certain way of 
THE ABC OF SOCIAL LEARNING

1001

1002

1003

1004

1005

1006

1007

1008

1009

1010

1011

1012

1013

1014

1015

1016

1017

1018

1019

1020

1021

1022

1023

1024

1025

1026

1027

1028

doing things, the knower ascribes value to their behavior, and in turn directs the focus of the learner.

This may imply that cognitively complex processes are not necessary: for instance, full-blown ToM may become superfluous in this instance, as learners are not required to infer concrete intentions but merely some unspecified goals in the knower involved. Overall, relying on an affective dimension in the model allows lowering the high cognitive thresholds proposed by a cognitive-only approach, while not denying the particular requisites at each step, offering a solution in both the evolutionary and developmental debates at stake.

\section{Connecting traditions to obtain a complete picture of social learning}

While one of our aims was to blend affect into theoretical models of cultural learning (ASL in particular aims at explaining how individuals learn to feel about something, which has deep cultural consequences, see below), our principal objective was also to reconcile three strands of research that seem to have either ignored or even denigrated each other (e.g. Boesch, 2007). In our view, all three approaches are valid and can describe and illuminate a particular side of knowledge acquisition in both humans and non-humans (e.g. Table 1). Only by precisely describing every aspect can we obtain a complete picture of the learning processes, as well as their comparability across species and developmental stages. Yet, given that three different elements (affective, behavioral and cognitive output) appear involved in parallel in the cases described so far, it may be complicated to define clear-cut steps characterized by particular degrees of cognitive complexity or the importance of emotion in the learning processes; hence, the involvement of each of the three elements may have to be described separately for any given scenario. This is, of course, common practice in science, as researchers reduce a particular phenomenon to observable and measurable parts for convenience. The $\mathrm{ABC}$ approach puts the three-part story of social learning back together again, superimposing the three dimensions of Affect, Behavior and Cognition while acknowledging their specificities. Even when similarly organized along the lines of intentional behavior, all dimensions can thus be considered independently from each other, giving overall more flexibility for analysis. For example, it is possible that a grown-up adult who normally engages with a toddler using pedagogy incites the latter to engage with a new device by simply 
THE ABC OF SOCIAL LEARNING

1029

1030

1031

1032

1033

1034

1035

1036

1037

1038

1039

1040

1041

1042

1043

1044

1045

1046

1047

1048

1049

1050

1051

1052

1053

1054

1055 interacting with it (stimulus enhancement) while pretending to ignore the toddler to foster her curiosity: in such a case, from the view of the child, there is no interaction with the model, while the model herself displays fully developed ToM to pretend that she is not aware that her actions will modify her toddler's goals. Similarly, the amount of feedback received by the learner can vary from an emotional experience (e.g. a female chimpanzee scared to approach an experimental task), to a precise technique (e.g. how to manufacture a stick to extract honey from a $\log$ ), to the instructions to follow to successfully complete a particular task (so far limited to humans).

In effect, it is possible to describe (emotional) contagion, (affective) observation, social referencing and (natural) pedagogy cases in affective, behavioral, and cognitive terms (Table 1). For some, the work appears straightforward: as described above, social referencing has been both used in emotional and cognitive contexts in the literature, despite the fact that that one dimension is unlikely to go without the other. And, notably, whether the focus was on the cognitive or affective context, successful referencing was often measured in term of the presence or absence of resulting behavior. It stems from these studies that infants are able to appreciate, deliberately seek out, and incorporate information (such as intentional emotional expressions and knowledge about the world, broadly speaking) from trusted adults into their decision-making process about the encountered emotionally or epistemically uncertain situation. Perhaps this is moderated by the ability to not only appreciate the relation between the other and her goal or the relevant object, but also the desire to understand the other by reading her emotions, and by the motivation to seek out information from the knowledgeable other, and by the relationship between the two people. A similar approach can be used for affective observation and natural pedagogy. In addition, it is possible to equally describe what happens in other species, highlighting where differences occur with human development.

\section{Table 1}

Applying the $\mathrm{ABC}$ approach to social learning cases in the real world 
THE ABC OF SOCIAL LEARNING

\begin{tabular}{|c|c|c|c|}
\hline Examples & Affective approach & Behavioral approach & Cognitive approach \\
\hline $\begin{array}{l}\text { A young boy learning } \\
\text { to tie his shoes }\end{array}$ & $\begin{array}{l}\text { He is excited, motivated } \\
\text { and interested in learning a } \\
\text { new skill } \\
\text { He is curious about how } \\
\text { this is done } \\
\text { He is frustrated when not } \\
\text { succeeding at first } \\
\text { He recognizes and } \\
\text { responds to his mother's } \\
\text { praise } \\
\text { He is overjoyed when } \\
\text { succeeding, pushing him to } \\
\text { restart immediately }\end{array}$ & $\begin{array}{l}\text { He observes the end point } \\
\text { left by his mother (a node } \\
\text { made on the other shoe) } \\
\text { He observes the behavioral } \\
\text { form produced by his mother } \\
\text { to tie her own node } \\
\text { He attends to the modeling of } \\
\text { his mother }\end{array}$ & $\begin{array}{l}\text { He imagines the shape of the } \\
\text { node to be made } \\
\text { He represents the exact moves } \\
\text { that need to be made to obtain } \\
\text { the node as demonstrated by } \\
\text { his mother } \\
\text { He recognizes his mother's } \\
\text { intention to teach him } \\
\text { He asks his mother for help or } \\
\text { instructions (to explain or } \\
\text { demonstrate) }\end{array}$ \\
\hline $\begin{array}{l}\text { A young chimpanzee } \\
\text { learning to crack nuts }\end{array}$ & $\begin{array}{l}\text { He feels that cracking nuts } \\
\text { is safe as his mother does } \\
\text { not demonstrate visible } \\
\text { fear } \\
\text { He recognizes his mother } \\
\text { is interested in her tool- } \\
\text { using activity } \\
\text { He is sufficiently interested } \\
\text { (perhaps because he is } \\
\text { hungry?) to attend to his } \\
\text { mother's display rather } \\
\text { than play with other } \\
\text { juveniles } \\
\text { Once he succeeds, he feels } \\
\text { a heightened anticipation } \\
\text { toward the cracked nut, } \\
\text { and then enjoyment as he } \\
\text { eats it. He is motivated to } \\
\text { continue }\end{array}$ & $\begin{array}{l}\text { He observes the end result (a } \\
\text { cracked nut) } \\
\text { He observes the behavioral } \\
\text { form produced by a } \\
\text { knowledgeable individual } \\
\text { He produces a sequence of } \\
\text { actions aiming at opening the } \\
\text { nut }\end{array}$ & $\begin{array}{l}\text { He represents the end state of } \\
\text { the nut (a cracked nut) } \\
\text { He associates hammering and } \\
\text { obtaining a cracked nut } \\
\text { He notices his cracking } \\
\text { behavior does not result in } \\
\text { obtaining a cracked nut } \\
\text { He attends to the tool-using } \\
\text { activity of his mother }\end{array}$ \\
\hline $\begin{array}{l}\text { A young girl aiming to } \\
\text { cross the road where } \\
\text { her sibling has already } \\
\text { crossed }\end{array}$ & $\begin{array}{l}\text { She is afraid of crossing } \\
\text { because a very fast car just } \\
\text { passed } \\
\text { She is anxious of being } \\
\text { scolded by her siblings if } \\
\text { they are late } \\
\text { She trusts her siblings' } \\
\text { judgement that the road is } \\
\text { safe to cross }\end{array}$ & $\begin{array}{l}\text { She displays behavior clues } \\
\text { that she wants to join her } \\
\text { siblings who have already } \\
\text { crossed the road } \\
\text { She observes her siblings on } \\
\text { the other side of the road, } \\
\text { who are gesturing and calling } \\
\text { towards her }\end{array}$ & $\begin{array}{l}\text { She represents her siblings' } \\
\text { goal: they want her to cross the } \\
\text { road } \\
\text { She understands that they will } \\
\text { be late if she does not cross. } \\
\text { She does not want to make } \\
\text { them wait and risk being late } \\
\text { for dinner } \\
\text { She asks her sister for } \\
\text { guidance how to cross the road } \\
\text { safely }\end{array}$ \\
\hline $\begin{array}{l}\text { A young chimpanzee } \\
\text { crossing the road when } \\
\text { his group has already } \\
\text { crossed }\end{array}$ & $\begin{array}{l}\text { She is afraid of crossing } \\
\text { because a very fast car just } \\
\text { passed } \\
\text { She feels the tense } \\
\text { situation in other } \\
\text { individuals being alert } \\
\text { when crossing the road } \\
\text { She does not get upset as } \\
\text { the behavior of the alpha } \\
\text { male is not threatening }\end{array}$ & $\begin{array}{l}\text { She displays behavior clues } \\
\text { that she wants to join the rest } \\
\text { of the group on the other side } \\
\text { of the road } \\
\text { She observes the alpha male } \\
\text { waiting on the other side and } \\
\text { looking back towards her }\end{array}$ & $\begin{array}{l}\text { She recognizes the danger } \\
\text { associated with crossing the } \\
\text { road } \\
\text { She knows she is likely to } \\
\text { encounter humans (or hear } \\
\text { them) while crossing the road } \\
\text { She notices the lack of fear } \\
\text { expression in the alpha male's } \\
\text { facial expression }\end{array}$ \\
\hline
\end{tabular}


THE ABC OF SOCIAL LEARNING

1056

1057 Application of the ABC approach to the evolution of culture and language

1058

1059

In this final section, we illustrate how the $\mathrm{ABC}$ approach can shed some new light on a diversity of 1060 phenomena spanning from cultural learning to the occurrence and proliferation of language 1061 conventions, language and signal comprehension and acquisition. In each of these cases, affect, in 1062 parallel to cognition, facilitates the occurrence and fixation of the feature in a given group, leading to the appropriate behavior involved in the feature in question. To underline the use of our approach, in what follows, we explain how an $\mathrm{ABC}$ approach contributes to a paradigmatic change of describing 1065 these features and their occurrences through cognition, affect and behavior in unison.

1066

While definitions of social cognition have perhaps principally focused on the mental states of others 1068 and predictions of their behavior (on others, Baillargeon, Scott, \& Bian, 2016; Fiske \& Taylor, 2013), 1069 one alternative, as exemplified in our $\mathrm{ABC}$ approach, is to focus on the information itself (from others, 1070 Clément, 2010; Harris, 2012). Accordingly, the study of the affective information provided to us by 1071 others falls under the term 'social appraisal': whether someone tells us that a film is worth watching, or that we have to decide whether the majority or expert minority are better sources of information, we are taking into consideration other people's affective views about an object. Both adults and infants as young as 3-years-old trust more the testimony of people who look happy than those who look angry, easing their learning (Clément, Bernard, Grandjean, \& Sander, 2013). Incorporating this 'affective testimony' (Clément \& Dukes, 2017; Harris, 2019) as part of a general social appraisal in the ABC approach is mandatory, and is in line with Manstead and Fischer's original goals for the scope of social appraisal (Fischer \& van Kleef, 2010; Manstead \& Fischer, 2001; Parkinson \& Manstead, 2015).

The introduction of affect as a means to control knowledge transmission can apply as much to deciding to engage in an emotionally-charged ritual in traditional or ancient human societies, as it can to chimpanzees approaching an unknown nut, experimentally introduced in their environment (Biro et al., 2003). In the latter case, we do not expect the added folklore, stories, and abstract values attached to 
1084

1085

1086

1087

1088

1089

1090

1091

1092

1093

1094

1095

1096

1097

1098

1099

1100

1101

1102

1103

1104

1105

1106

1107

1108

1109

1110

1111

the human rituals to appear, but the emotional connection to an unknown experience may well favor or, on the contrary, force the disappearance of a given behavior present in the community, adding to the ecological variables that already impact the maintenance of the behavior in the first place (Grund, Neumann, Zuberbühler, \& Gruber, 2019). The ABC approach can also add clarity to several contentious issues related to animal culture. For example, there has been much debate on the type of conformity present in animals (van Leeuwen, Kendal, Tennie, \& Haun, 2015; Whiten \& van de Waal, 2016). Conformity is particularly challenging because it is founded on complex metarepresentational processes (Gruber, et al., 2015). One may however argue that original studies of conformity (Asch, 1956) or bystander effect (Latane \& Darley, 1968) included affective statements by knowledgeable participants, which influenced the way the naïve participants behaved. This affective dimension may well be at play in animal conformity cases, offering a less cognitively-loaded account, which still does not deny the reality of the phenomenon observed in non-humans.

The ABC approach can also be proposed for complex species-specific cultural phenomena such as language evolution in humans. Building on evolutionary approaches that aim to lower the cognitive threshold for studying their occurrence in other species (for imitation learning in the acquisition of novel words, see Fridland \& Moore, 2014; for intentionality in communication, see Townsend, et al., 2017), we believe that the $\mathrm{ABC}$ approach can provide a more accurate perspective on language evolution than current models that heavily rely on cognitive mechanisms. The main issue for these approaches is how to explain the occurrence of language conventions without relying on traditional descriptions such as the one by Lewis (1969). Lewis claimed that for language conventions to occur, i.e., for words to have the property of being context-independently meaningful, we all, as part of a language community, indirectly committed to using the word in a certain way and we are actively aware of these agreements (that is, member $\mathrm{X}$ of language community $\mathrm{L}$ knows that member $\mathrm{Y}$ of the same language community also knows that word $\mathrm{W}$ means $\mathrm{M}$ and uses it in accordance with that meaning). Human language conventions though are not infinitely stable, but dynamic; novel language conventions are introduced through novel uses of signals by language users (e.g., a prime example consists of the use of novel words used by adolescents, that can eventually become part of established dictionaries). According to 
1112 Lewis, the novel use is detected by other members of the language community through grasping the 1113 intentions involved on the speaker's side when producing a word with a novel meaning. To grasp these 1114 intentions, established research traditionally describes the context, previous meanings of the word, and 1115 additional ostensive signals by the speaker, all of which are used as premises (e.g. Sperber \& Wilson, 1116 1995). The entire process is usually assumed to be highly cognitively loaded, making arbitrarily meaningful signals and language conventions per se one of the defining and exclusive features of human 1118 communication versus other animals' (e.g. Scott-Phillips, 2015). Compared to these accounts, evolutionary accounts consider that the level of cognitive requirements for language conventions to appear and remain in circulation are too complex, especially when aiming to provide a narration of an evolutionary continuum (Millikan 2005; Moore 2013). Millikan for instance claims that while a speaker may intentionally start using a word in a novel way, a recipient, while not excluding it, does not need to focus on the speaker's intention; this is because the latter is rather interested in the use (or 'function' in Millikan's words) of this new word to describe the world (Millikan, 2005; for more discussion, see Sievers, Wild, \& Gruber, 2017). In addition, a word's meaning remains in use (that is, the word has a 'proliferation history' in Millikan's words) because using the word with its meaning fulfils this function (Millikan, 2005), i.e. using the word grizzly bear, referring to the presence of the particular species of bear, serves the function of warning and survival, which has allowed the variant to remain in the population. This is opposed to other approaches that claim that words remain in use because of the known intentions involved in all members of the language community (i.e. Lewis, 1969), and with that complex mindreading capacities involved (i.e., inferring the intention used by communicator when using a word in a novel way, see Bloom, 2002).

While the Millikanian 'function' of a word is certainly an important factor for the proliferation, we believe the actual proliferation mechanisms might be linked to the ascription of value for using a word in a certain way (Sievers \& Gruber, 2020). It is claimed that for young children to learn language conventions - thereby guaranteeing the proliferation of the convention - complex learning (i.e., imitation learning) and teaching processes are involved in grasping arbitrary meanings of words (Moore 2013). ASL may help explaining how these processes come about in a less cognitively challenging 
manner: communicators engaging with a certain object linked to the novel meaning of the signal ascribe

1141 value to the object for the novel word use. For example, adolescent children may see several or one 1142 particularly influential peer using a word in a certain context with a certain meaning, and ascribe value 1143 to it, meaning that there is importance to this use of the word for the adolescent child. That is, the peer 1144 ascribes value to the use by producing the word in the given context, and makes the adolescent drawn 1145 to this way of usage. In a next step, for the adolescent child to gain more information about the concrete 1146 usage and, with that, the meaning of the word, again affective states play an important role: facial expressions as displays of affective states (Ekman \& Friesen, 1978; but see Fridlund, 1994) are often considered ostensive signals during communication (Wharton \& Saussure, 2020). These ostensive signals are important tools to direct attention to the relevant information for understanding the word use and with that its precise meaning. In this manner the important peer may 'teach' the adolescent the use of the word, in a non-active way.

Overall, affective states and value ascription are an important part of introducing language conventions (i.e. novel word uses), and the identification of these involved affective states or valuable objects are central for other community members to grasp this new meaning. The $\mathrm{ABC}$ approach here may help explain the exact learning and attention-getting processes that are involved. In particular, while not excluding complex ToM-based processes for the establishment of novel convention, adopting an $\mathrm{ABC}$ approach does not deny the possibility for less cognitively-centered processes. This is particularly important while considering language evolution, for example, the different degrees of arbitrariness found in animal signals, which may allow for an evolutionary continuous explanation for the appearance of full-blown arbitrary meaningful signals such as human words, from less-arbitrary beginnings as can

1162 be found in other great apes (Sievers \& Gruber, 2020).

\section{Conclusion}

1165

1166 In this article, we have argued that the current literatures on social learning and affective social 1167 influence, for historical reasons more than apparent theoretical disagreements, have remained divided. 
1168 Yet, besides the frustration of being unable to maneuver across disciplines concerned with a similar 1169 object of study, we have argued that it is crucial to recognize striking commonalities. We have proposed 1170 a novel ABC approach of social learning, including Affect, Behavior and Cognition, building on the 1171 three major traditions that we have reviewed in the literature. Our attempts at reviewing these three 1172 major domains have been necessarily patchy. For example, we have only superficially reviewed the major debates in the social learning literature between animal and human social learning, which has

1174 occupied much of the debate on the uniqueness of human culture over the last two decades. Yet, we 1175 also believe that this debate has reached a stand-still, with scholars on both sides (animal culture 1176 proponents and sceptics, respectively) unable to convince the others to join them at the theoretical level 1177 (Gruber, 2016; Tennie, et al., 2009; Whiten, et al., 2009). Our proposal to include affect in the debate can, we hope, unlock the stalemate, as well as contribute to the debates in the developmental literature with respect to the (non-affective) cognitive achievement of infants and toddlers (Gredebäck, Astor, \& Fawcett, 2018; Heyes, 2017).

Overall, we believe that scientists should strive to integrate affect as part of any social learning model, as it is likely to always color one's perception of one's environment. Affect provides a continuum, from uncontrollable tantrums present in babies of many species, to the faculty to manipulate, consciously or not, the appreciation of a learner of a given object of its environment, whether animated or not. We believe that the $\mathrm{ABC}$ approach thus not only provides a bridge between species, but also highlights that any social learning process will be somehow influenced by its affect, as largely studied and demonstrated in other domains by affective sciences. While we do not believe that animal and human social learning theories have completely ignored affect, we believe the latter deserves a much more central place in the debate, and we hope that our contribution will foster discussions between the three major branches of social learning, as well as with other disciplines such as affective neurosciences (see also Olsson, et al., 2020), that can lead to the reconstruction of the evolution of the mind as a product of affect, behavior and cognition. In this respect, we have briefly described potential important applications of the $\mathrm{ABC}$ approach, in providing a scaffold for the evolution of culture and language. 
THE ABC OF SOCIAL LEARNING

1196

1197

1198

1199

1200

1201

1202

1203

1204

1205

1206

1207

1208

1209

1210

1211

1212

1213

1214

1215

1216

1217

1218

1219

1220

can be used as a starting point to determine how emotion and cognition kept interacting throughout our evolution, rendering our cultures and communications unique in scope and nature

Notes: 1. Interestingly, this approach to motivation appears to depart from the usual use of the term in emotion research where it refers to event-induced states of relatively short duration where one is inclined to act or not to act (Frijda, 2010).

\section{Acknowledgments}

We thank colleagues at the Swiss Center for Affective Sciences for stimulating discussions on this topic. We would like to thank Cambridge University Press for permission to use and adapt the figures. We would also like to thank three anonymous reviewers for their thoughtful comments, which have improved the quality of our manuscript.

\section{Funding statement}

TG was supported by a grant from the Swiss National Science Foundation (grant PCEFP1_186832) during the writing of this article.

\section{References}

Adolph, K. E., Kaplan, B. E., \& Kretch, K. S. (in press). Infants on the edge: Beyond the visual cliff. In A. Slater \& P. Quinn (Eds.), Developmental psychology: Revisiting the classic studies, 2nd ed. London: Sage Publications.

Albuquerque, N., Guo, K., Wilkinson, A., Savalli, C.,, Otta, E., \& Mills, D. (2016). Dogs recognize dog and human emotions. Biol. Lett., 12, 20150883. doi: http://doi.org/10.1098/rsbl.2015.0883

Allen, J., Weinrich, M., Hoppitt, W., \& Rendell, L. (2013). Network-based diffusion analysis reveals cultural transmission of lobtail feeding in humpback whales. Science, 340, 485-488. doi: $10.1126 /$ science. 1231976 
THE ABC OF SOCIAL LEARNING

1221

1222

1223

1224

1225

1226

1227

1228

1229

1230

1231

1232

1233

1234

1235

1236

1237

1238

1239

1240

1241

1242

1243

1244

1245

1246

1247

1248

Arango-Muñoz, S., \& Michaelian, K. (2014). Epistemic feelings, epistemic emotions: review and introduction to the focus section. Philosophical Inquiries, 2, 97-117.

Asch, S. E. (1956). Studies of independence and conformity: I. A minority of one against a unanimous majority. Psychological Monographs: General and Applied, 70, 1-70.

Baillargeon, R., Scott, R. M., \& Bian, L. (2016). Psychological Reasoning in Infancy. Annual Review of Psychology, 67(1), 159-186. doi: 10.1146/annurev-psych-010213-115033

Baldwin, D. A., \& Moses, L. J. (1996). The Ontogeny of Social Information Gathering. Child Development, 67(5), 1915-1939. doi: 10.1111/j.1467-8624.1996.tb01835.x

Bandini, E., \& Tennie, C. (2017). Spontaneous reoccurrence of "scooping", a wild tool-use behaviour, in naïve chimpanzees. PeerJ, 5, e3814. doi: 10.7717/peerj.3814

Bandura, A. (1977). Social Learning Theory. New York: General Learning Press.

Banse, R., \& Scherer, K. R. (1996). Acoustic profiles in vocal emotion expression. Journal of Personality and Social Psychology, 70, 614-636.

Baron-Cohen, S. (2005). Autism--"Autos": Literally, a Total Focus on the Self? The lost self: Pathologies of the brain and identity (pp. 166-180). New York, NY, US: Oxford University Press.

Bateson, P., \& Mameli, M. (2007). The innate and the acquired: Useful clusters or a residual distinction from folk biology? Developmental Psychobiology, 49(8), 818-831. doi: $10.1002 / \mathrm{dev} .20277$

Bazhydai, M., Silverstein, P., Parise, E., \& Westermann, G. (2020). Two-year-old children preferentially transmit simple actions but not pedagogically demonstrated actions. Developmental Science, e12941.

Bazhydai, M., Twomey, K., \& Westermann, G. (2020). Curiosity and exploration. In J. B. Benson (Ed.), Encyclopedia of Infant and Early Childhood Development, 2nd edition (pp. 370-378): Elsevier.

Bazhydai, M., Westermann, G., \& Parise, E. (2020). "I don't know but I know who to ask": 12-montholds actively seek information from knowledgeable adults. Developmental Science, $n / a(\mathrm{n} / \mathrm{a})$, e12938. doi: 10.1111/desc.12938 
THE ABC OF SOCIAL LEARNING

Begus, K., \& Southgate, V. (2012). Infant pointing serves an interrogative function. Developmental Science, 15(5), 611-617. doi: 10.1111/j.1467-7687.2012.01160.x

Begus, K., \& Southgate, V. (2018). Curious learners: How infants' motivation to learn shapes and is shaped by infants' interactions with the social world. In M. Saylor \& P. Ganea (Eds.), Active Learning from Infancy to Childhood. Cham: Springer.

Berlyne, D. E. (1960). Conflict, Arousal, and Curiosity. New York, NY, US: McGraw-Hill Book Company.

Biro, D., Inoue-Nakamura, N., Tonooka, R., Yamakoshi, G., Sousa, C., \& Matsuzawa, T. (2003). Cultural innovation and transmission of tool use in wild chimpanzees: Evidence from field experiments. Animal Cognition, 6, 213-223.

Bloom, P. (2002). Mindreading, communication and the learning of names for things. Mind \& Language, 17, 37-54.

Boesch, C. (2007). What makes us human (Homo sapiens)? The challenge of cognitive cross-species comparison. Journal of Comparative Psychology, 121(3), 227-240.

Boyd, R., Richerson, P. J., \& Henrich, J. (2011). The cultural niche: Why social learning is essential for human adaptation. Proceedings of the National Academy of Sciences, 201100290. doi: 10.1073/pnas. 1100290108

Brand, R. J., Baldwin, D. A., \& Ashburn, L. A. (2002). Evidence for "motionese": Modifications in mothers' infant directed action. Developmental Science, 5( 72-83).

Broesch, T. L., \& Bryant, G. A. (2015). Prosody in infant-directed speech is similar across Western and traditional cultures. Journal of Cognition and Development, 16(1), 31-43. doi: $10.1080 / 15248372.2013 .833923$

Brosseau-Liard, P. E., \& Poulin-Dubois, D. (2014). Sensitivity to Confidence Cues Increases during the Second Year of Life. Infancy, 19(5), 461-475. doi: 10.1111/infa.12056

Bruder, M., Fischer, F., \& Manstead, A. S. R. (2014). Social appraisal as cause of collective emotions. In C. Von Scheve \& M. Salmela (Eds.), Collective emotions: Perspectives from psychology, philosophy, and sociology (pp. 141-155). Oxford, UK: Oxford University Press. 
THE ABC OF SOCIAL LEARNING

1276 Buttelmann, D., Carpenter, M., \& Tomasello, M. (2009). Eighteen-month-old infants show false 1277 belief understanding in an active helping paradigm. Cognition, 112(2), 337-342. doi: https://doi.org/10.1016/j.cognition.2009.05.006

1279

1280

1281

1282

1283

1284

1285

1286

1287

1288

1289

1290

1291

1292

1293

1294

1295

1296

1297

1298

1299

1300

1301

1302

1303

Buttelmann, D., Zmyj, N., Daum, M. M., \& Carpenter, M. (2013). Selective imitation of in-group over out-group members in 14-month-olds. Child Development, 84, 422-428.

Byrne, R. W. (2002). Imitation of novel complex actions: What does the evidence from animals mean? In P. J. B. Slater, J. S. Rosenblatt, C. T. Snowdon \& T. J. Roper (Eds.), Advances in the Study of Behavior (Vol. 31, pp. 77-105): Academic Press.

Caldwell, C. A., Schillinger, K., Evans, C., \& Hopper, L. (2012). End state copying by humans (Homo sapiens): Implications for a comparative perspective on cumulative culture. Journal of Comparative Psychology, 126, 161-169.

Calero, C. I., Zylberberg, A., Ais, J., Semelman, M., \& Sigman, M. (2015). Young children are natural pedagogues. Cognitive Development, 35, 65-78. doi: 10.1016/j.cogdev.2015.03.001

Call, J., Carpenter, M., \& Tomasello, M. (2005). Copying results and copying actions in the process of social learning: chimpanzees (Pan troglodytes) and human children (Homo sapiens). Animal Cognition, 8(3), 151-163.

Campos, J. J., Mumme, D. L., Kermoian, R., \& Campos, R. G. (1994). A functionalist perspective on the nature of emotion. Monographs of the Society for Research in Child Development, 59(23), 284-303. doi: 10.1111/j.1540-5834.1994.tb01289.x

Caro, T. M., \& Hauser, M. D. (1992). Is there evidence of teaching in nonhuman animals? Quarterly Review of Biology, 67, 151-174.

Chow, V., Poulin-Dubois, D., \& Lewis, J. (2008). To see or not to see: infants prefer to follow the gaze of a reliable looker. Developmental Science, 11(5), 761-770. doi: 10.1111/j.14677687.2008.00726.x

Clément, F. (2010). To Trust or not to Trust? Children's Social Epistemology. Review of Philosophy and Psychology, 1(4), 531-549. doi: 10.1007/s13164-010-0022-3

Clément, F., Bernard, S., Grandjean, D., \& Sander, D. (2013). Emotional expression and vocabulary learning in adults and children. Cognition and Emotion, 27, 539-548. 
THE ABC OF SOCIAL LEARNING

1304 Clément, F., \& Dukes, D. (2013). The role of interest in the transmission of social values. [Hypothesis 1305 and Theory]. Frontiers in Psychology, 4(349). doi: 10.3389/fpsyg.2013.00349

1306 Clément, F., \& Dukes, D. (2017). Social Appraisal and Social Referencing: Two Components of 1307 Affective Social Learning. Emotion Review, 9(3), 253-261. doi: 10.1177/1754073916661634

1308 Clément, F., \& Dukes, D. (2020). Affective Social Learning serves as a quick and flexible complement to TTOM. Behavioral and Brain Sciences, 43, e99. doi:

Corriveau, K. H., Ronfard, S., \& Cui, Y. K. (2018). Cognitive mechanisms associated with children's selective teaching. Review of Philosophy and Psychology, 9, 831-848.

Crivelli, C., Russell, J. A., Jarillo, S., \& Fernández-Dols, J.-M. (2016). The fear gasping face as a threat display in a Melanesian society. Proceedings of the National Academy of Sciences, 113(44), 12403-12407. doi: 10.1073/pnas.1611622113

Csibra, G. (2010). Recognizing Communicative Intentions in Infancy. Mind \& Language, 25(2), 141168. doi: 10.1111/j.1468-0017.2009.01384.x

Csibra, G., \& Gergely, G. (2009). Natural pedagogy. Trends in Cognitive Sciences, 13, 148-153.

de Waal, F. B. M. (2001). The ape and the sushi master. London: Penguin.

de Waal, F. B. M. (2011). What is an animal emotion? Annals of the New York Academy of Sciences, 1224(1), 191-206. doi: 10.1111/j.1749-6632.2010.05912.x 
THE ABC OF SOCIAL LEARNING

1330

1331

1332

1333

1334

1335

1336

1337

1338

1339

1340

1341

1342

1343

1344

1345

1346

1347

1348

1349

1350

1351

1352

1353

1354

1355

1356

de Waal, F. B. M., \& Bonnie, K. E. (2009). In tune with others: The social side of primate culture. In K. N. Laland \& B. G. Galef (Eds.), The question of animal culture (pp. 19-39). Cambridge, MA: Harvard University Press.

de Waal, F. B. M., \& Preston, S. D. (2017). Mammalian empathy: behavioural manifestations and neural basis. Nature Reviews Neuroscience, 18(8), 498-509. doi: 10.1038/nrn.2017.72

Debiec, J., \& Olsson, A. (2017). Social Fear Learning: from Animal Models to Human Function. Trends in Cognitive Sciences, 21(7), 546-555. doi: 10.1016/j.tics.2017.04.010

Debracque, C., Gruber, T., Lacoste, R., Grandjean, D., \& Meguerditchian, A. (2021). Validating the use of functional Near-Infrared Spectroscopy in monkeys: The case of brain activation lateralization in Papio anubis. Behavioural Brain Research, 403, 113133. doi: https://doi.org/10.1016/j.bbr.2021.113133

Defeyter, M. A., \& German, T. P. (2003). Acquiring an understanding of design: Evidence from children's insight problem solving. Cognition, 89, 133-155. doi: 10.1016/S00100277(03)00098-2

Dennett, D. C. (1987). The intentional stance. Cambridge, Mass.: MIT Press.

DiYanni, C., \& Kelemen, D. (2008). Using a bad tool with good intention: Young children's imitation of adults' questionable choices. Journal of Experimental Child Psychology, 101, 241-261.

Dukes, D., \& Clément, F. (2017). Author Reply: Clarifying the importance of ostensive communication in life-long, affective social learning. Emotion Review, 9, 267-269.

Dukes, D., \& Clément, F. (Eds.). (2019). Foundations of Affective Social Learning: Conceptualizing the Social Transmission of Value. Cambridge: Cambridge University Press.

Dunn, K., \& Bremner, J. G. (2017). Investigating looking and social looking measures as an index of infant violation of expectation. Developmental Science, 20(6), e12452. doi: $10.1111 /$ desc. 12452

Egyed, K., Király, I., \& Gergely, G. (2013). Communicating Shared Knowledge in Infancy. Psychological Science, 24(7), 1348-1353. doi: 10.1177/0956797612471952

Ekman, P. (1992). An argument for basic emotions. Cognition \& Emotion, 6, 169-200. 
THE ABC OF SOCIAL LEARNING

1357

1358

1359

1360

1361

1362

1363

1364

1365

1366

1367

1368

1369

1370

1371

1372

1373

1374

1375

1376

1377

1378

1379

1380

1381

1382

1383

Ekman, P., \& Friesen, W. V. (1978). Facial action coding system. Palo Alto: Consulting Psychologist Press.

Farroni, T., Csibra, G., Simion, F., \& Johnson, M. H. (2002). Eye contact detection in humans from birth. Proceedings of the National Academy of Sciences, 99(14), 9602-9605. doi: 10.1073/pnas.152159999

Feinman, S., Roberts, D., Hsieh, K. F., Sawyer, D., \& Swanson, D. (1992). A critical review of social referencing in infancy. In S. Feinman (Ed.), Social referencing and the social construction of reality in infancy (pp. 15-54): Springer US.

Fernald, A. (1985). Four-month-old infants prefer to listen to motherese. Infant behavior and development, 8, 181-195.

Fischer, A. H., \& van Kleef, G. A. (2010). Where have all the people gone? A plea for including social interaction in emotion research. Emotion Review, 2(3), 208-211. doi: $10.1177 / 1754073910361980$

Fiske, S. T., \& Taylor, S. E. (2013). Social Cognition: From Brains to Culture. London: Sage.

Flynn, E., \& Whiten, A. (2010). Studying children's social learning experimentally in the wild. Learning \& Behavior, 38, 284-296.

Frick, A., Clément, F., \& Gruber, T. (2017). Evidence for a sex effect during overimitation: boys copy irrelevant modelled actions more than girls across cultures. Royal Society Open Science, 4(12). doi: $10.1098 /$ rsos. 170367

Fridland, E., \& Moore, R. (2014). Imitation reconsidered. Philosophical Psychology, 28, 856-880.

Fridlund, A. J. (1994). Human facial expressions: An evolutionary perspective. New York: Academic Press.

Frijda, N. H. (2010). Impulsive action and motivation. Biological Psychology, 84(3), 570-579. doi: https://doi.org/10.1016/j.biopsycho.2010.01.005

Frijda, N. H., \& Tcherkassof, A. (1997). Facial expressions as modes of action readiness The psychology of facial expression. (pp. 78-102). Paris, France: Editions de la Maison des Sciences de l'Homme. 
THE ABC OF SOCIAL LEARNING

Fröhlich, M., Müller, G., Zeiträg, C., Wittig, R. M., \& Pika, S. (2017). Gestural development of chimpanzees in the wild: the impact of interactional experience. Animal Behaviour, 134, 271282. doi: https://doi.org/10.1016/j.anbehav.2016.12.018

Fuhrmann, D., Ravignani, A., Marshall-Pescini, S., \& Whiten, A. (2014). Synchrony and motor mimicking in chimpanzee observational learning. Scientific Reports, 4(1), 5283. doi: $10.1038 /$ srep05283

Galef, B. G., \& Whiten, A. (2017). The comparative psychology of social learning. In J. Call, G. Burghardt, I. Pepperberg, C. T. Snowdon \& T. R. Zentall (Eds.), APA handbook of comparative psychology (pp. 411-440). Washington, DC: American Psychological Association.

Gopnik, A. (2012). Scientific thinking in young children: Theoretical advances, empirical research, and policy implications. Science, 337, 1623-1627. doi: 10.1126/science.1223416

Gopnik, A., \& Wellman, H. M. (2012). Reconstructing constructivism: Causal models, Bayesian learning mechanisms, and the theory theory. Psychological Bulletin, 138, 1085-1108. doi: https://doi.org/10.1037/a0028044

Gottlieb, J., \& Oudeyer, P.-Y. (2018). Towards a neuroscience of active sampling and curiosity. Nature Reviews Neuroscience, 17, 1-13.

Goupil, L., Romand-Monnier, M., \& Kouider, S. (2016). Infants ask for help when they know they don't know. Proceedings of the National Academy of Sciences, 201515129. doi: $10.1073 /$ pnas. 1515129113

Grandjean, D., Sander, D., Pourtois, G., Schwartz, S., Seghier, M. L., Scherer, K. R., \& Vuilleumier, P. (2005). The voices of wrath: brain responses to angry prosody in meaningless speech. Nature Neuroscience, 8(2), 145-146.

Gredebäck, G., Astor, K., \& Fawcett, C. (2018). Gaze Following Is Not Dependent on Ostensive Cues: A Critical Test of Natural Pedagogy. Child Development, 89(6), 2091-2098. doi: 10.1111/cdev.13026 
THE ABC OF SOCIAL LEARNING

1410

1411

1412

1413

1414

1415

1416

1417

1418

1419

1420

1421

1422

1423

1424

1425

1426

1427

1428

1429

1430

1431

1432

1433

1434

1435

1436

1437

Greenfield, P. M. (1991). Language, Tools, and Brain - the Ontogeny and Phylogeny of Hierarchically Organized Sequential Behavior. Behavioral and Brain Sciences, 14(4), 531550.

Gruber, T. (2016). Great apes do not learn novel tool use easily: Conservatism, functional fixedness, or cultural influence? International Journal of Primatology, 37(2), 296-316. doi: $10.1007 / \mathrm{s} 10764-016-9902-4$

Gruber, T., Deschenaux, A., Frick, A., \& Clément, F. (2019). Group membership influences more social identification than social learning or overimitation in children. Child Development, 90 , 728-745. doi: 10.1111/cdev.12931

Gruber, T., \& Grandjean, D. (2017). A comparative neurological approach to emotional expressions in primate vocalizations. Neuroscience \& Biobehavioral Reviews, 73, 182-190.

Gruber, T., Muller, M. N., Reynolds, V., Wrangham, R. W., \& Zuberbühler, K. (2011). Communityspecific evaluation of tool affordances in wild chimpanzees. Scientific Reports, 1, 128. doi: $10.1038 /$ srep00128

Gruber, T., \& Sievers, C. (2019). Affective social learning and the emotional side of cultural learning in primates. In D. Dukes \& F. Clément (Eds.), Foundations of Affective Social Learning: Conceptualising the Transmission of Social Value (pp. 41-66). Cambridge: Cambridge University Press.

Gruber, T., Zuberbühler, K., Clément, F., \& van Schaik, C. P. (2015). Apes have culture but may not know that they do. Frontiers in Psychology, 6, 91. doi: 10.3389/fpsyg.2015.00091

Grund, C., Neumann, C., Zuberbühler, K., \& Gruber, T. (2019). Necessity creates opportunities for chimpanzee tool use. Behavioral Ecology, 30, 1136-1144.

Gweon, H., \& Schulz, L. (2019). From exploration to instruction: Children learn from exploration and tailor their demonstrations to observers' goals and competence. Child development, 90, e148e164.

Halberstadt, A., Hagan, C. A., \& Lozada, F. T. (in press). Emotions as fixatives for children's understandings about the world. In D. Dukes, A. C. Samson \& E. Walle (Eds.), The Oxford Handbook of Emotional Development, Oxford University Press. 
THE ABC OF SOCIAL LEARNING

1438

1439

1440

1441

1442

1443

1444

1445

1446

1447

1448

1449

1450

1451

1452

1453

1454

1455

1456

1457

1458

1459

1460

1461

1462

1463

1464

1465

Hareli, S., \& Hess, U. (2010). What emotional reactions can tell us about the nature of others: An appraisal perspective on person perception. Cognition and Emotion, 24(1), 128-140. doi: $10.1080 / 02699930802613828$

Harris, P. L. (2012). Trusting what you're told: How children learn from others. Cambridge, MA: Belknap Press/Harvard University Press.

Harris, P. L. (2019). Affective social learning: From nature to culture. In D. Dukes \& F. Clément (Eds.), Foundations of Affective Social Learning: Conceptualizing the Social Transmission of Value (pp. 69-86). Cambridge University Press.

Harris, P. L., Koenig, M. A., Corriveau, K. H., \& Jaswal, V. K. (2018). Cognitive Foundations of Learning from Testimony. Annual Review of Psychology, 69(1), 251-273. doi: 10.1146/annurev-psych-122216-011710

Harris, P. L., \& Lane, J. D. (2014). Infants understand how testimony works. Topoi, 33(2), 443-458. doi: 10.1007/s11245-013-9180-0

Haun, D. B. M., \& Over, H. (2013). Like me: A homophily-based account of human culture. In P.J. Richerson \& M. Christiansen (Eds.), Cultural evolution. Cambridge, MA, USA: MIT Press.

Hembacher, E., deMayo, B., \& Frank, M. C. (2020). Children's Social Information Seeking is Sensitive to Referential Ambiguity. Child Development, $n / a($ n/a). doi: 10.1111/cdev.13427

Henrich, J., Heine, S., \& Norenzayan, A. (2010). The weirdest people in the world? Behavioral and Brain Sciences, 33, 61-135.

Herrmann, E., Call, J., Hernandez-Lloreda, M. V., Hare, B., \& Tomasello, M. (2007). Humans have evolved specialized skills of social cognition: The cultural intelligence hypothesis. Science, 317(5843), 1360-1366.

Hertenstein, M. J., Keltner, D., App, B., Bulleit, B. A., \& Jaskolka, A. R. (2006). Touch communicates distinct emotions. Emotion, 6(3), 528-533. doi: 10.1037/1528-3542.6.3.528

Heyes, C. (2017). When does social learning become cultural learning? Developmental Science, 20(2), e12350. doi: 10.1111/desc. 12350

Heyes, C. (2018). Cognitive Gadgets: The Cultural Evolution of Thinking. Cambridge, MA: Harvard University Press. 
THE ABC OF SOCIAL LEARNING

1466

1467

1468

1469

1470

1471

1472

1473

1474

1475

1476

1477

1478

1479

1480

1481

1482

1483

1484

1485

1486

1487

1488

1489

1490

1491

1492

1493

Hickok, G. (2014). The myth of mirror neurons: The real neuroscience of communication and cognition. New York, NY, US: W W Norton \& Co.

Hidi, S. E., \& Renninger, K. A. (2020). On educating, curiosity, and interest development. Current Opinion in Behavioral Sciences, 35, 99-103.

Hobaiter, C., Poisot, T., Zuberbühler, K., Hoppitt, W., \& Gruber, T. (2014). Social network analysis shows direct evidence for social transmission of tool use in wild chimpanzees. PLOS Biology, 12(9), e1001960.

Hoehl, S., Keupp, S., Schleihauf, H., McGuigan, N., Buttelmann, D., \& Whiten, A. (2019). 'Overimitation': A review and appraisal of a decade of research. [doi:10.1016/j.dr.2018.12.002]. Developmental Review, 51, 90-108. doi: 10.1016/j.dr.2018.12.002

Horner, V., \& Whiten, A. (2005). Causal knowledge and imitation/emulation switching in chimpanzees (Pan troglodytes) and children (Homo sapiens). Animal Cognition, 8, 164-181.

Howe, N., Della Porta, S., Recchia, H., \& Ross, H. (2016). "Because if you don't put the top on, it will spill”: A longitudinal study of sibling teaching in early childhood. Developmental Psychology, 52, 1832-1842. doi: 10.1037/dev0000193

Huber, L., Popovová, N., Riener, S., Salobir, K., \& Cimarelli, G. (2018). Would dogs copy irrelevant actions from their human caregiver? Learning \& Behavior, 46(4), 387-397. doi: $10.3758 / \mathrm{s} 13420-018-0336-\mathrm{Z}$

Hygge, S., \& Öhman, A. (1978). Modeling processes in the acquisition of fears: Vicarious electrodermal conditioning to fear-relevant stimuli. Journal of Personality and Social Psychology, 36(3), 271-279. doi: 10.1037/0022-3514.36.3.271

Iacoboni, M. (2009). Imitation, Empathy, and Mirror Neurons. Annual Review of Psychology, 60(1), 653-670. doi: 10.1146/annurev.psych.60.110707.163604

Kachel, G., Moore, R., \& Tomasello, M. (2018). Two-year-olds use adults' but not peers' points. Developmental Science, 21(5), e12660. doi: 10.1111/desc.12660

Kavaliers, M., Choleris, E., \& Colwell, D. D. (2001). Learning from others to cope with biting flies: Social learning of fear-induced conditioned analgesia and active avoidance. Behavioral Neuroscience, 115(3), 661-674. doi: 10.1037/0735-7044.115.3.661 
THE ABC OF SOCIAL LEARNING

1494 Kelemen, D., \& Carey, S. (2007). The essence of artifacts: Developing the design stance. In E.

1495

1496

1497

1498

1499

1500

1501

1502

1503

1504

1505

1506

1507

1508

1509

1510

1511

1512

1513

1514

1515

1516

1517

1518

1519

1520

1521 Margolis \& S. Laurence (Eds.), Creations of the mind: Theories of artifacts and their representation (pp. 212-230). Oxford: OUP.

Kendal, R. L., Boogert, N. J., Rendell, L., Laland, K. N., Webster, M., \& Jones, P. L. (2018). Social Learning Strategies: Bridge-Building between Fields. Trends Cogn Sci, 22(7), 651-665. doi: 10.1016/j.tics.2018.04.003

Keupp, S., Behne, T., Zachow, J., Kasbohm, A., \& Rakoczy, H. (2015). Overimitation is not automatic: Context sensitivity in children's overimitation and action interpretation of causally irrelevant actions. Journal of Experimental Child Psychology, 130, 163-175.

Kline, M. A. (2014). How to learn about teaching: An evolutionary framework for the study of teaching behavior in humans and other animals. Behavioral and Brain Sciences, 38, e31. doi: $10.1017 / \mathrm{S} 0140525 \mathrm{X} 14000090$

Kline, M. A., Shamsudheen, R., \& Broesch, T. (2018). Variation is the universal: making cultural evolution work in developmental psychology. Philosophical transactions of the Royal Society of London. Series B, Biological sciences, 373(1743), 20170059. doi: 10.1098/rstb.2017.0059

Klinnert, M. D., Campos, J., Sorce, J. F., Emde, R. N., \& Svejda, M. J. (1983). Social referencing: Emotional expressions as behavior regulators. Emotion: Theory, research and experience, 2, $57-86$.

Koechlin, E., \& Jubault, T. (2006). Broca's area and the hierarchical organization of human behavior. Neuron, 50, 963-974. doi: 10.1016/j.neuron.2006.05.017

Koenig, M. A., \& Echols, C. H. (2003). Infants' understanding of false labeling events: the referential roles of words and the speakers who use them. Cognition, 87(3), 179-208. doi: https://doi.org/10.1016/S0010-0277(03)00002-7

Krause, M. A., \& Domjan, M. (2017). Ethological and evolutionary perspectives on Pavlovian conditioning APA handbook of comparative psychology: Perception, learning, and cognition, Vol. 2 (pp. 247-266). Washington, DC, US: American Psychological Association.

Lamon, N., Neumann, C., Gruber, T., \& Zuberbühler, K. (2017). Kin-based cultural transmission of tool use in wild chimpanzees. Science Advances, 3(4), e1602750. 
THE ABC OF SOCIAL LEARNING

1522

1523

1524

1525

1526

1527

1528

1529

1530

1531

1532

1533

1534

1535

1536

1537

1538

1539

1540

1541

1542

1543

1544

1545

1546

1547

Laporte, M. N. C., \& Zuberbühler, K. (2011). The development of a greeting signal in wild chimpanzees. Developmental Science, 14(5), 1220-1234. doi: 10.1111/j.14677687.2011.01069.x

Latane, B., \& Darley, J. M. (1968). Group inhibition of bystander intervention in emergencies. Journal of Personality and Social Psychology, 10(3), 215-221. doi: 10.1037/h0026570

Lazarus, R. S. (1991). Progress on a cognitive-motivational-relational theory of emotion. American Psychologist, 46(8), 819-834. doi: 10.1037/0003-066X.46.8.819

LeDoux, J. (2012). Rethinking the emotional brain. Neuron, 73, 653-676.

Lee, J.-S. (2012). The effects of the teacher-student relationship and academic press on student engagement and academic performance. Int. J. Educ. Res., 53, 330-340.

Leech, K. A., Haber, A. S., Arunachalam, S., Kurkul, K., \& Corriveau, K. H. (2019). On the malleability of selective trust. J Exp Child Psychol, 183, 65-74. doi: 10.1016/j.jecp.2019.01.013

Legare, C. H. (2017). Cumulative cultural learning: Development and diversity. Proceedings of the National Academy of Sciences, 114(30), 7877. doi: 10.1073/pnas.1620743114

Legare, C. H., \& Harris, P. L. (2016). The Ontogeny of Cultural Learning. Child Development, 87(3), 633-642. doi: 10.1111/cdev.12542

Lehrman, D. S. (1953). A Critique of Konrad Lorenz's Theory of Instinctive Behavior. The Quarterly Review of Biology, 28(4), 337-363. doi: 10.1086/399858

Lewis, D. (1969). Convention: A philosophical study. Cambridge, MA: Harvard University Press.

Li, Y., Liao, Y., Cheng, Y., \& He, J. (2019). Group conquers efficacy: Preschoolers' imitation under conflict between minimal group membership and behavior efficacy. PLOS ONE, 14(9), e0223101. doi: 10.1371/journal.pone.0223101

Liszkowski, U., Carpenter, M., \& Tomasello, M. (2008). Twelve-month-olds communicate helpfully and appropriately for knowledgeable and ignorant partners. Cognition, 108(3), 732-739. doi: 10.1016/j.cognition.2008.06.013 
THE ABC OF SOCIAL LEARNING

Luchkina, E., Corriveau, K. H., \& Sobel, D. M. (2020). I don’t believe what you said before: Preschoolers retrospectively discount information from inaccurate speakers. Journal of Experimental Child Psychology, 189, 104701. doi: https://doi.org/10.1016/j.jecp.2019.104701

Lyons, D. E., Young, A. G., \& Keil, F. C. (2007). The hidden structure of overimitation. Proceedings of the National Academy of Sciences, 104, 19751-19756. doi: 10.1073/pnas.0704452104

Mandler, J. M. (2007). The conceptual foundations of animals and artifacts. In E. Margolis \& S. Laurence (Eds.), Creations of the mind: Theories of artifacts and their representation (pp. 191-211). Oxford: OUP.

Mann, J., Stanton, M. A., Patterson, E. M., Bienenstock, E. J., \& Singh, L. O. (2012). Social networks reveal cultural behaviour in tool-using dolphins. [Article]. Nature Communications, 3, 980. doi: $10.1038 /$ ncomms1983

Manstead, A. S. R., \& Fischer, A. H. (2001). Social appraisal: The social world as object of and influence on appraisal processes Appraisal processes in emotion: Theory, methods, research. (pp. 221-232). New York, NY: Oxford University Press.

Marler, P. (2004). Innateness and the instinct to learn. Anais da Academia Brasileira de Ciências, 76, 189-200.

McGuigan, N., Makinson, J., \& Whiten, A. ( 2011). From over-imitation to super-copying: Adults imitate causally irrelevant aspects of tool use with higher fidelity than young children. $B r . J$. Psychol., 102, 1-18.

Meltzoff, A. N. (1995). Understanding the Intentions of Others - Reenactment of Intended Acts by 18Month-Old Children. Developmental Psychology, 31(5), 838-850.

Meltzoff, A. N. (2007). 'Like me': A foundation for social cognition. Developmental Science 10, 126134.

Merola, I., Lazzaroni, M., Marshall-Pescini, S., \& Prato-Previde, E. (2015). Social referencing and cat-human communication. Animal cognition, 18, 639-648.

Merola, I., Prato-Previde, E., \& Marshall-Pescini, S. (2012). Dogs' social referencing towards owners and strangers. PLOS ONE, 7, e47653. 
THE ABC OF SOCIAL LEARNING

1575

1576

1577

1578

1579

1580

1581

1582

1583

1584

1585

1586

1587

1588

1589

1590

1591

1592

1593

1594

1595

1596

1597

1598

1599

1600

1601

Mertens, G., Raes, A. K., \& De Houwer, J. (2016). Can prepared fear conditioning result from verbal instructions? Learning and Motivation, 53, 7-23. doi: 10.1016/j.lmot.2015.11.001

Meylan, A. (2014). Epistemic emotions: a natural kind? Philosophical Inquiries, 2, 173-191.

Millikan, R. G. (2005). Language: A Biological Model. Oxford: Oxford University Press.

Mireault, G. C., Crockenberg, S. C., Sparrow, J. E., Pettinato, C. A., Woodard, K. C., \& Malzac, K. (2014). Social looking, social referencing and humor perception in 6- and-12-month-old infants. Infant Behavior and Development, 37(4), 536-545. doi: https://doi.org/10.1016/j.infbeh.2014.06.004

Morgan, T. J. H., Uomini, N. T., Rendell, L. E., Chouinard-Thuly, L., Street, S. E., Lewis, H. M., . . Laland, K. N. (2015). Experimental evidence for the co-evolution of hominin tool-making teaching and language. [Article]. Nature Communications, 6. doi: 10.1038/ncomms7029

Mortillaro, M., \& Dukes, D. (2018). Jumping for Joy: The Importance of the Body and of Dynamics in the Expression and Recognition of Positive Emotions. [Perspective]. Frontiers in Psychology, 9(763). doi: 10.3389/fpsyg.2018.00763

Moses, L. J., Baldwin, D. A., Rosicky, J. G., \& Tidball, G. (2001). Evidence for referential understanding in the emotions domain at twelve and eighteen months. Child Development, 72, 718-735.

Musgrave, S., Lonsdorf, E., Morgan, D., Prestipino, M., Bernstein-Kurtycz, L., Mundry, R., \& Sanz, C. (2020). Teaching varies with task complexity in wild chimpanzees. Proceedings of the National Academy of Sciences, 117(2), 969-976. doi: 10.1073/pnas.1907476116

Nicol, C. J., \& Pope, S. J. (1996). The maternal feeding display of domestic hens is sensitive to perceived chick error. Animal Behaviour, 52(4), 767-774. doi: 10.1006/anbe.1996.0221

Nielsen, M. (2006). Copying actions and copying outcomes: Social learning through the second year. Developmental Psychology, 42, 555-565.

Nielsen, M., Haun, D., Kärtner, J., \& Legare, C. H. (2017). The persistent sampling bias in developmental psychology: A call to action. Journal of Experimental Child Psychology, 162(Supplement C), 31-38. doi: https://doi.org/10.1016/j.jecp.2017.04.017 
THE ABC OF SOCIAL LEARNING

1602

1603

1604

1605

1606

1607

1608

1609

1610

1611

1612

1613

1614

1615

1616

1617

1618

1619

1620

1621

1622

1623

1624

1625

1626

1627

1628

Nielsen, M., \& Tomaselli, K. (2010). Overimitation in Kalahari Bushmen and the origins of human cultural cognition. Psychol Sci., 5, 729-736.

Olsson, A., Knapska, E., \& Lindström, B. (2020). The neural and computational systems of social learning. Nature Reviews Neuroscience, 21(4), 197-212. doi: 10.1038/s41583-020-0276-4

Olsson, A., Nearing, K. I., \& Phelps, E. A. (2007). Learning fears by observing others: the neural systems of social fear transmission. Social cognitive and affective neuroscience, 2(1), 3-11. doi: $10.1093 / \mathrm{scan} / \mathrm{nsm} 005$

Olsson, A., \& Phelps, E. A. (2004). Learned fear of "unseen" faces after Pavlovian, observational, and instructed fear. Psychol Sci, 15(12), 822-828. doi: 10.1111/j.0956-7976.2004.00762.x

Olsson, A., \& Phelps, E. A. (2007). Social learning of fear. Nat Neurosci, 10(9), 1095-1102. doi: $10.1038 / \mathrm{nn} 1968$

Oostenbroek, J., Suddendorf, T., Nielsen, M., Redshaw, J., Kennedy-Costantini, S., Davis, J., . . . Slaughter, V. (2016). Comprehensive Longitudinal Study Challenges the Existence of Neonatal Imitation in Humans. Current Biology, 26(10), 1334-1338. doi: 10.1016/j.cub.2016.03.047

Over, H., \& Carpenter, M. (2013). The social side of imitation. Child Development Perspectives, 7, 611.

Panksepp, J. (1998). Affective neuroscience: The foundations of human and animal emotions. New York, NY: Oxford University Press.

Panksepp, J. (2005). Affective consciousness: Core emotional feelings in animals and humans. Consciousness and Cognition, 14, 30-80.

Panksepp, J. (2011a). The basic emotional circuits of mammalian brains: Do animals have affective lives? Neuroscience \& Biobehavioral Reviews, 35(9), 1791-1804. doi: 10.1016/j.neubiorev.2011.08.003

Panksepp, J. (2011b). Cross-species affective neuroscience decoding of the primal affective experiences of humans and related animals. [doi:10.1371/journal.pone.0021236]. PLOS ONE, 6(9), e21236. 
THE ABC OF SOCIAL LEARNING

1629

1630

1631

1632

1633

1634

1635

1636

1637

1638

1639

1640

1641

1642

1643

1644

1645

1646

1647

1648

1649

1650

1651

1652

1653

1654

1655

Panksepp, J. B., \& Panksepp, J. (2017). Empathy through the ages: A comparative perspective on rodent models of shared emotion APA handbook of comparative psychology: Perception, learning, and cognition, Vol. 2 (pp. 765-792). Washington, DC, US: American Psychological Association.

Paradise, R., \& Rogoff, B. (2009). Side by Side: Learning by Observing and Pitching In. Ethos, 37(1), 102-138. doi: 10.1111/j.1548-1352.2009.01033.x

Parkinson, B. (2011). Interpersonal emotion transfer: Contagion and social appraisal. Social and Personality Psychology Compass, 5, 428-439.

Parkinson, B., \& Manstead, A. S. R. (2015). Current Emotion Research in Social Psychology: Thinking About Emotions and Other People. Emotion Review, 7(4), 371-380. doi: $10.1177 / 1754073915590624$

Pekrun, R. (2017). Achievement emotions. In A. J. Elliot, C. S. Dweck \& D. S. Yeager (Eds.), Handbook of com-petence and motivation: Theory and application (pp. 251-271). New York, NY: The Guilford Press.

Piaget, J. (1952). Play, dreams, and imitation in childhood: Heinemann.

Pons, F., Harris, P. L., \& de Rosnay, M. (2004). Emotion comprehension between 3 and 11 years: Developmental periods and hierarchical organization. [doi: 10.1080/17405620344000022]. European Journal of Developmental Psychology, 1(2), 127-152. doi: $10.1080 / 17405620344000022$

Poulin-Dubois, D., Brooker, I., \& Polonia, A. (2011). Infants prefer to imitate a reliable person. Infant Behavior \& Development, 34(2), 303-309. doi: 10.1016/j.infbeh.2011.01.006

Poulin-Dubois, D., \& Brosseau-Liard, P. (2016). The Developmental Origins of Selective Social Learning. Current Directions in Psychological Science, 25(1), 60-64. doi: $10.1177 / 0963721415613962$

Price, T., Wadewitz, P., Cheney, D., Seyfarth, R., Hammerschmidt, K., \& Fischer, J. (2015). Vervets revisited: A quantitative analysis of alarm call structure and context specificity. Scientific Reports, 5, 13220. 
THE ABC OF SOCIAL LEARNING

1656

1657

1658

1659

1660

1661

1662

1663

1664

1665

1666

1667

1668

1669

1670

1671

1672

1673

1674

1675

1676

1677

1678

1679

1680

1681

1682

1683

Reschke, P. J., Walle, E. A., \& Dukes, D. (2017). Interpersonal Development in Infancy: The Interconnectedness of Emotion Understanding and Social Cognition. Child Development Perspectives, 11(3), 178-183. doi: 10.1111/cdep.12230

Reschke, P. J., Walle, E. A., \& Dukes, D. (2020). Did you mean to do that? Infants use emotional communication to infer and re-enact others' intended actions. Cognition and Emotion, 34(7), 1473-1479. doi: 10.1080/02699931.2020.1745760

Richerson, P. J., \& Boyd, R. (2005). Not by genes alone: How culture transformed human evolution. Chicago and London: University of Chicago Press.

Rogoff, B. (2003). The cultural nature of human development. New York, NY, US: Oxford University Press.

Rogoff, B., Mistry, J., Göncü, A., Mosier, C., Chavajay, P., \& Heath, S. B. (1993). Guided Participation in Cultural Activity by Toddlers and Caregivers. Monographs of the Society for Research in Child Development, 58(8), i-179. doi: 10.2307/1166109

Ronfard, S., Zambrana, I. M., Hermansen, T. K., \& Kelemen, D. (2018). Question-asking in childhood: A review of the literature and a framework for understanding its development. Developmental Review, 49, 101-120. doi: 10.1016/j.dr.2018.05.002

Ryan, R. M., \& Deci, E. L. (2020). Intrinsic and extrinsic motivation from a self-determination theory perspective: Definitions, theory, practices, and future directions. Contemporary Educational Psychology, 61, 101860. doi: https://doi.org/10.1016/j.cedpsych.2020.101860

Saarni, C. (1979). Children's understanding of display rules for expressive behavior. Developmental Psychology, 15, 424-429.

Sander, D. (2013). Models of emotion: the affective neuroscience approach Handbook of Human Affective Neuroscience. Cambridge: Cambridge University Press.

Sauter, D. A., Eisner, F., Ekman, P., \& Scott, S. K. (2010). Cross-cultural recognition of basic emotions through nonverbal emotional vocalizations. PNAS, 107, 2408-2412.

Saylor, M. M., \& Ganea, P. A. (Eds.). (2018). Active learning from infancy to childhood: Social motivation, cognition, and linguistic mechanisms: Springer.

Schaffer, H. R. (1984). The child's entry into a social world. New York: Academic. 
THE ABC OF SOCIAL LEARNING

1684

1685

1686

1687

1688

1689

1690

1691

1692

1693

1694

1695

1696

1697

1698

1699

1700

1701

1702

1703

1704

1705

1706

1707

1708

1709

1710

1711

Scherer, K. R. (2005). What are emotions? And how can they be measured? Social Science Information, 44(4), 695-729. doi: 10.1177/0539018405058216

Scherer, K. R., Schorr, A., \& Johnstone, T. (Eds.). (2001). Appraisal processes in emotion: Theory, methods, research. New York, NY, US: Oxford University Press.

Schleihauf, H., \& Hoehl, S. (2020). A dual-process perspective on over-imitation. Developmental Review, 55, 100896. doi: https://doi.org/10.1016/j.dr.2020.100896

Schultz, W. (2006). Behavioral Theories and the Neurophysiology of Reward. Annual Review of Psychology, 57(1), 87-115. doi: 10.1146/annurev.psych.56.091103.070229

Schulz, L. (2012). The origins of inquiry: inductive inference and exploration in early childhood. Trends Cogn Sci, 16(7), 382-389. doi: 10.1016/j.tics.2012.06.004

Schuppli, C., Forss, S., Meulman, E. J. M., Zweifel, N., Lee, K. C., Rukmana, E., . . van Schaik, C. P. (2016). Development of foraging skills in two orangutan populations: needing to learn or needing to grow? Frontiers in Zoology, 13(1), online.

Schuppli, C., \& van Schaik, C. P. (2019). Social learning in orang-utans: is it affective? In D. Dukes \& F. Clément (Eds.), Foundations of Affective Social Learning: Conceptualizing the Social Transmission of Value. Cambridge: Cambridge University Press.

Scott-Phillips, T. C. (2015). Speaking Our Minds. London: Palgrave Macmillan.

Seyfarth, R. M., \& Cheney, D. L. (1986). Vocal development in vervet monkeys. Animal Behaviour, $34,1640-1658$.

Shafto, P., Goodman, N. D., \& Frank, M. C. (2012). Learning From Others: The Consequences of Psychological Reasoning for Human Learning. Perspectives on Psychological Science, 7(4), 341-351. doi: 10.1177/1745691612448481

Shettleworth, S. J. (1998). Cognition, evolution, and behavior. Oxford: Oxford University Press.

Sievers, C., \& Gruber, T. (2020). Can nonhuman primate signals be arbitrarily meaningful like human words? An affective approach. Animal Behavior and Cognition.

Sievers, C., Wild, M., \& Gruber, T. (2017). Intentionality and flexibility in animal communication In K. Andrews \& J. Beck (Eds.), Routledge Handbook of Philosophy of Animal Minds (pp. 333342). London and New York: Routledge. 
THE ABC OF SOCIAL LEARNING

1712 Silvia, P. J., \& Kashdan, T. B. (2009). Interesting things and curious people: Exploration and

1713 engagement as transient states and enduring strengths. Social and Personality Psychology

1714

1715

1716

1717

1718

1719

1720

1721

1722 Compass, 3(5), 785-797. doi: 10.1111/j.1751-9004.2009.00210.x

Slaughter, V. (2021). Do Newborns Have the Ability to Imitate? Trends Cogn Sci. doi: 10.1016/j.tics.2021.02.006

Slocombe, K. E., Kaller, T., Call, J., \& Zuberbühler, K. (2010). Chimpanzees extract social information from agonistic screams. PLoS ONE, 5(7), e11473. doi: 10.1371/journal.pone.0011473

Sobel, D. M., \& Kushnir, T. (2013). Knowledge matters: How children evaluate the reliability of testimony as a process of rational inference. Psychological Review, 120, 779-797. doi: https://doi.org/10.1037/a0034191

Sorce, J. F., Emde, R. N., Campos, J., \& Klinnert, M. D. (1985). Maternal emotional signaling: Its effect on the visual cliff behavior of 1-year-olds. Developmental Psychology, 21, 195-200.

Southgate, V. (2020). Are infants altercentric? The other and the self in early social cognition. Psychol Rev, 127(4), 505-523. doi: 10.1037/rev0000182

Spelke, E., Bernier, E. P., \& Skerry, A. E. (2013). Core social cognition. In R. Mahzarin, M. R. Banaji \& S. A. G. SA (Eds.), Navigating the socialworld. What infants, children, and other species can teach us (pp. 11-16). Oxford: Oxford University Press.

Sperber, D., \& Wilson, D. (1995). Relevance: Communication and Cognition, second edition. Malden, Mass: Blackwell.

Stenberg, G. (2003). Effects of maternal inattentiveness on infant social referencing. Infant and Child Development: An International Journal of Research and Practice, 12, 399-419. doi: $10.1002 /$ icd. 321

Stenberg, G. (2013). Do 12-Month-Old Infants Trust a Competent Adult? Infancy, 18(5), 873-904. doi: 10.1111/infa.12011

Stenberg, G., \& Hagekull, B. (2007). Infant Looking Behavior in Ambiguous Situations: Social Referencing or Attachment Behavior? Infancy, 11(2), 111-129. doi: 10.1111/j.15327078.2007.tb00218.x 
THE ABC OF SOCIAL LEARNING

1740 Stevens, F. L., Hurley, R. A., Taber, K. H., Hurley, R. A., Hayman, L. A., \& Taber, K. H. (2011).

1741

1742

1743

1744

1745

1746

1747

1748

1749

1750

1751

1752

1753

1754

1755

1756

1757

1758

1759

1760

1761

1762

1763

1764

1765

Anterior Cingulate Cortex: Unique Role in Cognition and Emotion. The Journal of Neuropsychiatry and Clinical Neurosciences, 23(2), 121-125. doi: 10.1176/jnp.23.2.jnp121

Strauss, S., Calero, C. I., \& Sigman, M. (2014). Teaching, naturally. Trends in Neuroscience and Education, 3, 38-43. doi: 10.1016/j.tine.2014.05.001

Striano, T., Vaish, A., \& Benigno, J. P. (2006). The meaning of infants' looks: Information seeking and comfort seeking? British Journal of Developmental Psychology, 24(3), 615-630. doi: $10.1348 / 026151005 \times 67566$

Tennie, C., Call, J., \& Tomasello, M. (2009). Ratcheting up the ratchet: on the evolution of cumulative culture. Philosophical Transactions of the Royal Society B, 364, 2045-2415.

Thornton, A., \& McAuliffe, K. (2006). Teaching in wild meerkats. Science, 313(5784), 227-229.

Tomasello, M. (1999). The cultural origins of human cognition. Cambridge, MA: Harvard University Press.

Tomasello, M. (2008). Origins of Human Communication. Cambridge, MA: MIT Press.

Tomasello, M. (2009). Why we cooperate. Cambridge, MA: MIT Press.

Tomasello, M. (2016). A Natural History of Human Morality. Boston, MA: Harvard University Press.

Tomasello, M., Carpenter, M., Call, J., Behne, T., \& Moll, H. (2005). Understanding and sharing intentions: The origins of cultural cognition. Behavioral and Brain Sciences, 28(5), 675-735.

Tompkins, S. S. (1963). Affect, imagery, consciousness: II. The Negative Affects. Oxford, England: Springer.

Tong, Y., Wang, F., \& Danovitch, J. (2020). The role of epistemic and social characteristics in children's selective trust: Three meta-analyses. Developmental Science, 23(2), e12895. doi: $10.1111 /$ desc. 12895

Townsend, S., Koski, S., Byrne, R., Slocombe, K., Bickel, B., Braga Goncalves, I., . . Manser, M. B. (2017). Exorcising Grice's ghost: an empirical approach to studying intentional communication in animals. Biological Reviews, 92(3), 1427-1433. doi: 10.1111/brv.12289 
THE ABC OF SOCIAL LEARNING

1766

1767

1768

1769

1770

1771

1772

1773

1774

1775

1776

1777

1778

1779

1780

1781

1782

1783

1784

1785

1786

1787

1788

1789

1790

1791

1792

1793

Tummeltshammer, K. S., Wu, R., Sobel, D. M., \& Kirkham, N. Z. (2014). Infants Track the Reliability of Potential Informants. Psychological Science, 25(9), 1730-1738. doi: $10.1177 / 0956797614540178$

van Leeuwen, E. J. C., Kendal, R. L., Tennie, C., \& Haun, D. B. M. (2015). Conformity and its looka-likes. Animal Behaviour, 110, e1-e4. doi: 10.1016/j.anbehav.2015.07.030

Vredenburgh, C., Kushnir, T., \& Casasola, M. (2015). Pedagogical cues encourage toddlers' transmission of recently demonstrated functions to unfamiliar adults. Developmental science, $18,645-654$.

Vygotsky, L. S. (1987). The development of scientific concepts in childhood. The collected works of LS Vygotsky, 1, 167-241.

Walden, T. A. (1991). Infant social referencing The development of emotion regulation and dysregulation. (pp. 69-88). New York, NY, US: Cambridge University Press.

Want, S. C., \& Harris, P. L. (2002). How do children ape? Applying concepts from the study of nonhuman primates to the developmental study of 'imitation' in children. Dev. Sci., 5(1), 1-41.

Warneken, F., \& Tomasello, M. (2006). Altruistic Helping in Human Infants and Young Chimpanzees. Science, 311(5765), 1301-1303. doi: 10.1126/science.1121448

Wharton, T., \& Saussure, L. d. (2020). Relevance, effects and affect. International Review of Pragmatics, 12, xx.

Wheeler, B. C., \& Fischer, J. (2012). Functionally referential signals: a promising paradigm whose time has passed. Evolutionary Anthropology, 21, 195-205.

Whiten, A., Goodall, J., McGrew, W. C., Nishida, T., Reynolds, V., Sugiyama, Y., . . Boesch, C. (1999). Cultures in chimpanzees. Nature, 399(6737), 682-685.

Whiten, A., McGuigan, N., Marshall-Pescini, S., \& Hopper, L. M. (2009). Emulation, imitation, overimitation and the scope of culture for child and chimpanzee. Philosophical Transactions of the Royal Society B: Biological Sciences, 364, 2417-2428.

Whiten, A., \& van de Waal, E. (2016). Identifying and dissecting conformity in animals in the wild: Further analysis of primate data. Animal Behaviour, 122, e1-e4. doi: 10.1016/j.anbehav.2016.04.002 
THE ABC OF SOCIAL LEARNING

1794 Yamamoto, S., Humle, T., \& Tanaka, M. (2012). Chimpanzees' flexible targeted helping based on an 1795 understanding of conspecifics' goals. Proceedings of the National Academy of Sciences, 1796 109(9), 3588-3592. doi: 10.1073/pnas.1108517109

1797 Zarbatany, L., \& Lamb, M. E. (1985). Social referencing as a function of information source: Mothers 1798 versus strangers. Infant Behavior and Development, 8, 25-33.

Zentall, T. R., \& Galef, J., B. G. (1988). Social learning: Psychological and biological perspectives. Hillsdale, NJ: Erlbaum.

Zmyj, N., Buttelmann, D., Carpenter, M., \& Daum, M. M. (2010). The reliability of a model influences 14-month-olds' imitation. Journal of Experimental Child Psychology, 106(4), 208220. doi: https://doi.org/10.1016/j.jecp.2010.03.002

Zmyj, N., Daum, M. M., Prinz, W., Nielsen, M., \& Aschersleben, G. (2012). Fourteen-Month-Olds' Imitation of Differently Aged Models. Infant and Child Development, 21(3), 250-266. doi: $10.1002 /$ icd. 750

Zuberbuhler, K. (2000). Causal cognition in a non-human primate: field playback experiments with Diana monkeys. Cognition, 76(3), 195-207.

Zwirner, E., \& Thornton, A. (2015). Cognitive requirements of cumulative culture: teaching is useful but not essential. Scientific Reports, 5, 16781. 
THE ABC OF SOCIAL LEARNING

\section{Box 1}

1813

1814

1815

1816

1817

1818

1819

1820

1821

1822

1823

1824

1825

1826

1827

1828

1829

1830

1831

1832

1833

1834

1835

1836

1837

1838

Understanding emotions in others' actions

Humans are notorious for their ability to express and understand emotions (Sauter, Eisner, Ekman, \& Scott, 2010; Scherer, 2005). Our understanding of emotions grows gradually; from an early onset already identifiable in the first year of life, at the end of which infants are able to recognize positive and negative facial expressions and to respond appropriately (Sorce, et al., 1985), to age 10 or 11 when they can recognize most facial expressions (Pons, Harris, \& de Rosnay, 2004). In the process, they also understand the social underpinnings of emotions and will attribute the correct 'emotion' to a given story (Saarni, 1979). While the universality of specific emotions is a continuous source of debate (Crivelli, Russell, Jarillo, \& Fernández-Dols, 2016; Ekman, 1992), the ability to recognize how conspecifics relate to the objects in their surroundings is nevertheless very likely to be present in all human societies suggesting that there is an evolutionary advantage to being able to do so. While being able to understand immediately that a conspecific is scared (Olsson \& Phelps, 2007), disgusted or angry, there may be evolutionary benefits too in appreciating that someone is proud, enthusiastic or interested (Mortillaro \& Dukes, 2018). The concept of social appraisal (Manstead \& Fischer, 2001) highlights how a learner can use others' appraisals of an object while appraising the object themselves. In simple terms, we can learn how others evaluate the objects in the environment: we may learn that an otherwise ignored object is in fact relevant, and then engage with it ourselves, we may also assume that members of the same group feel the same way and prefer learning from them (Gruber, et al., 2019). Observation of other people's manifestations of their relation with an object and subsequent inferences about how they feel towards the object, can inform the learner about how they should feel about the object themselves and predict how the other might behave (Egyed, Király, \& Gergely, 2013).

According to appraisal theorists, emotions are the result of the goals and motivations that an individual has on the other object (Campos, Mumme, Kermoian, \& Campos, 1994; Lazarus, 1991; Scherer, Schorr, \& Johnstone, 2001). Emotion can thus be directly seen in the action of the other and contextual (e.g. bodily) information may be quasi-automatically integrated, presumably even before an emotion is fully 
THE ABC OF SOCIAL LEARNING

1839

1840

1841

1842

1843

1844

1845

1846

1847

1848

1849

1850

1851

1852

1853

1854

1855

1856

1857

1858

1859

1860

1861

1862

1863

1864

1865

1866

identified for categorization (Frijda \& Tcherkassof, 1997): in line with Dennett's (1987) intentional stance, to grasp the sense of relational activity, "merely requires that movements be viewed as behavior - that is, as purposive, as movements related to the organism's environment and as guided by aims in relation to that environment" (Frijda \& Tcherkassof, 1997, p.95-96).

Social referencing is often described as comprised of two behavioral elements: initiating a look at the adult and using adult's emotional cues in guiding further actions (Walden, 1991). The focus on the visual modality for emotion recognition likely results from the propensity of infants to pay special attention to human faces, which may underlie their predisposition to learn about the world through a caregiver's face (Farroni, Csibra, Simion, \& Johnson, 2002). With development, looking at others allows them to obtain crucial feedback on the situation. As described in the main text, infants use social gaze to emotionally check in with their caregivers upon encountering a potentially dangerous situation, such as an obstacle on their path, a barking dog or a spider. This process is not limited to humans, as has been demonstrated in domesticated cats and dogs when dealing with humans within interspecific social referencing protocols (Merola, Lazzaroni, Marshall-Pescini, \& Prato-Previde, 2015; Merola, Prato-Previde, \& Marshall-Pescini, 2012).

Additional emotion clues can be found in the vocal (Banse \& Scherer, 1996) and tactile modalities (Hertenstein, Keltner, App, Bulleit, \& Jaskolka, 2006). Vocally communicated transmission may work better in some contexts, particularly when vocal communication is the only way to transmit such emotional information (Grandjean et al., 2005). This also opens experimental opportunities for investigating emotion recognition in other species. Comparative work indeed often relies on field experiments using vocal play-back, which offers a strong methodological approach in natural settings to explore the connections between affect and the social world. For example, chimps show 'surprise', in terms of longer orienting responses, when they have heard what they think is a lower-ranked member challenge a higher-ranked member of the group (Slocombe, Kaller, Call, \& Zuberbühler, 2010). Such recognition is not limited to primates, with dogs having been shown to recognize both conspecific and heterospecific (human) emotional content in vocalizations (Albuquerque et al., 2016). 